Article

\title{
Evaluation of Green and Grey Flood Mitigation Measures in Rural Watersheds
}

\author{
Ranko Pudar $^{1,2}$, Jasna Plavšić ${ }^{2}$ (I) and Andrijana Todorović ${ }^{2, *}$ \\ 1 Pudar Mitigation Consulting, Inc., P.O. Box 680725, Marietta, GA 30068, USA; \\ ranko_pudar@pudarconsulting.com or rpudar@grf.bg.ac.rs \\ 2 Faculty of Civil Engineering, University of Belgrade, Bulevar kralja Aleksandra 79, 11000 Belgrade, Serbia; \\ jplavsic@grf.bg.ac.rs \\ * Correspondence: atodorovic@grf.bg.ac.rs
}

Received: 30 July 2020; Accepted: 30 September 2020; Published: 2 October 2020

check for updates

\begin{abstract}
Floods cause considerable damages worldwide and mitigation of their adverse effects through effective protection measures is needed. Along with the commonly applied "grey" infrastructure, "green" measures that can offer additional benefits, such as ecosystem services, are increasingly being considered lately. While the recent research tendencies are focused on the effectiveness and the value of green measures in urban areas, this paper presents a comprehensive financial evaluation of green and grey flood mitigation scenarios for a smaller rural watershed. A micro-scale damage model that builds on the hydrodynamic modeling of hazard, detailed asset identification, and damage assessment is presented and applied for evaluation of benefits from various flood mitigation measures in the Tamnava watershed in Serbia. Four scenarios are considered: (1) existing flood protection system; (2) green scenario involving new detention basins; (3) grey infrastructure enhancement by rising of the existing levees and diverting flood discharges; and (4) green-grey scenario that combines scenarios (2) and (3). The benefits (loss reduction) are the greatest with the green scenario and marginally higher with the combined green-grey scenario. The results suggest that for small rural watersheds, a holistic, integrative approach that includes both types of infrastructure can provide the most effective flood risk mitigation.
\end{abstract}

Keywords: flood risk; flood damage; flood mitigation measures; green infrastructure; financial appraisals of damages; depth-damage functions; rural watersheds

\section{Introduction}

State and municipal governments are facing depleting natural resources, adverse climate change impacts, and many socio-economic challenges. Continuation of industrial, transportation, and utility services is critically dependent on continued construction and maintenance of roads, drainage infrastructure, culverts, etc., commonly known as "grey infrastructure".

Despite being essential for economic growth, these infrastructure investments are significant and continue throughout the life of any such project, through annual maintenance costs [1]. This point is of particular importance in infrastructure designed to provide protection from natural hazards, and specifically flood hazards. Large drainage systems and structural flood protection are being exposed to natural decay and require constant investment. They are characterized by a limited life span and declining benefits and are under additional stress by the changing climate [2,3]. Moreover, the human and the material assets protected by grey infrastructure are becoming more valuable over time, so the exposure to flood hazard grows even faster. Grey infrastructure also has a very limited role in ecosystem functions and can lead to degradation of local and regional systems [3]. 
In the process of looking for an alternative solution, attention is turning towards nature-based solutions ("green infrastructure") that could be used for mitigation of flood risks [4]. Green infrastructure (GI) is defined as "strategically planned network of natural and semi-natural areas that ... deliver a wide range of ecosystem services" [5]. Examples of applicable GI for flood risk mitigation are reclaimed wetlands, riverine floodplains, natural detentions, etc. Because of the growing challenges related to urban areas, such as population growth, rapid urbanization, and climate change effects, there has been abundant emergence of projects and research on coping with flood risk in urban areas using GI [6-11].

It has been shown in many cases that nature-based GI solutions are less expensive than grey infrastructure (e.g., [12]) and provide a wide array of co-benefits for local economies, the social fabric, and the broader environment [13]. This should be of particular interest to decision-makers, as GI can provide comparable benefits to grey infrastructure at reduced costs in the long term.

On the other hand, there has been very little research on the quantitative and cost effectiveness of GI for flood mitigation in settings other than urban, such as flat valleys of large rivers or small hilly watersheds prone to flash floods. One of the reasons for this is that improved understanding of trade-offs between flood risk reduction and economic consequences in rural settings is needed [2] because the assets in rural settings considerably differ from the ones in urban areas. Recently, the term "large-scale nature-based solutions" is commonly used for the flood risk mitigation measures in rural settings on either watershed or regional scale [4]. In small to medium size watersheds, flood risk reduction measures can vary from conventional grey infrastructure to various scales and levels of GI. In some cases, depending on the scale of the watershed, solutions gravitate towards larger scale nature-based solutions, or some combination of the green and grey infrastructure approach.

Both green and grey infrastructure as flood mitigation measures have their specific advantages and drawbacks and either may not be a universal solution to be applied indiscriminately to all types of watersheds and local conditions. Therefore, the two types of flood mitigation measures should not be a replacement for each other but should rather be considered as complementary measures $[12,14,15]$. For rural watersheds with some flood mitigation measures already present, the combination of green and grey infrastructure may be the most suitable solution.

Quantitative evaluation of different flood mitigation measures is necessary to select the most effective strategy for flood risk management or for adaptation to climate change [16]. The flood risk assessment, which is generally aimed at evaluating the potential consequences of floods [17], provides a basis for evaluating different mitigation options and making optimal decisions on flood mitigation measures. The flood risk assessment can also serve other various purposes such as identifying vulnerability of communities to floods, developing flood risk maps, or financial appraisals for the insurance sector [18].

The goal of this research is to identify a method of evaluating general flood mitigation strategy for smaller, predominately rural watersheds. The paper presents an evaluation of different flood mitigation scenarios (grey, green, and combined green and grey) for a small rural, agricultural watershed in Serbia through a comprehensive flood risk assessment of each option and their comparison. The evaluation is made with a spatial damage model based on combination of flood hazard and vulnerability assessments. The model can be characterized as the micro-scale flood damage model because it uses high-resolution hazard map outputs from the hydrodynamic modelling and fine-detail, multi-category assets data. The damage assessment is validated against the official post-disaster financial loss appraisals following a major flood event in the region in 2014, and therefore produces estimates of tangible direct and indirect losses with relatively low uncertainties. The flood mitigation options are compared in a traditional way by calculating benefits as avoided damages and losses. 


\section{Materials and Methods}

\subsection{Study Area and Flood Mitigation Options}

\subsubsection{Description of the Study Area}

The study area comprises upper watershed of river Tamnava and its tributaries Gračica and Ub, in central Serbia, approximately $60 \mathrm{~km}$ southwest of Belgrade, the capital. This area is a part of the larger Kolubara watershed, depicted in Figure 1. The Tamnava watershed covers $726 \mathrm{~km}^{2}$ and is primarily rural, with $79.3 \%$ of the area being cultivated land [19] (Figure 2). Urbanized and industrial land constitutes only $1.2 \%$ of the area and is concentrated in two small population centers, the towns of $\mathrm{Ub}$ and Koceljeva. The terrain elevation ranges from $470 \mathrm{~m}$ a.s.l. in upper reaches of the watershed to $64.4 \mathrm{~m}$ a.s.l. at its mouth (Figure 2), with arable land located in wide floodplains of the three rivers. The agricultural landscape consists primarily of small farms, with emphasis on several main crops. The rest of the economy is based on service industry located in towns of $\mathrm{Ub}$ and Koceljeva.

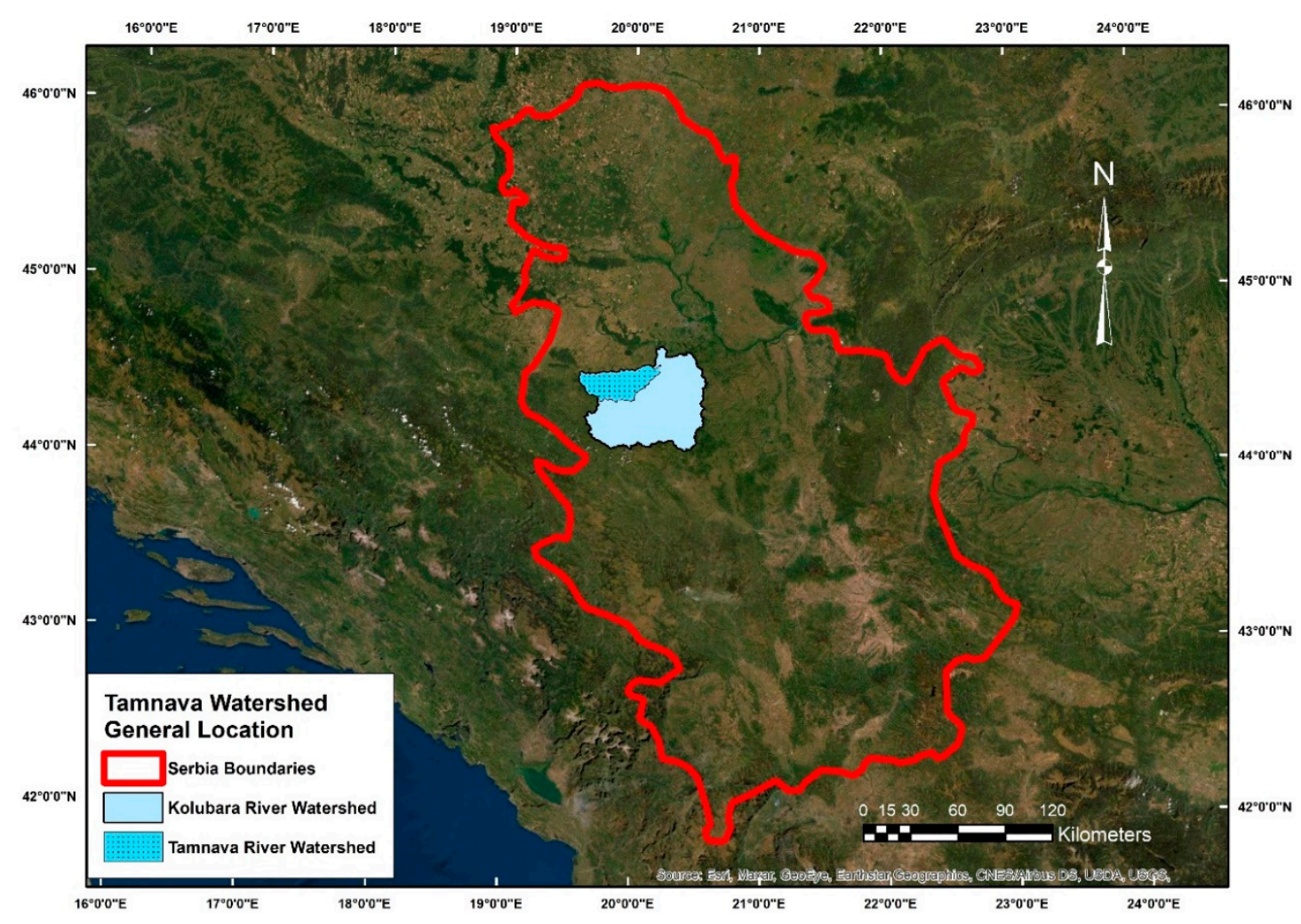

Figure 1. Cont. 


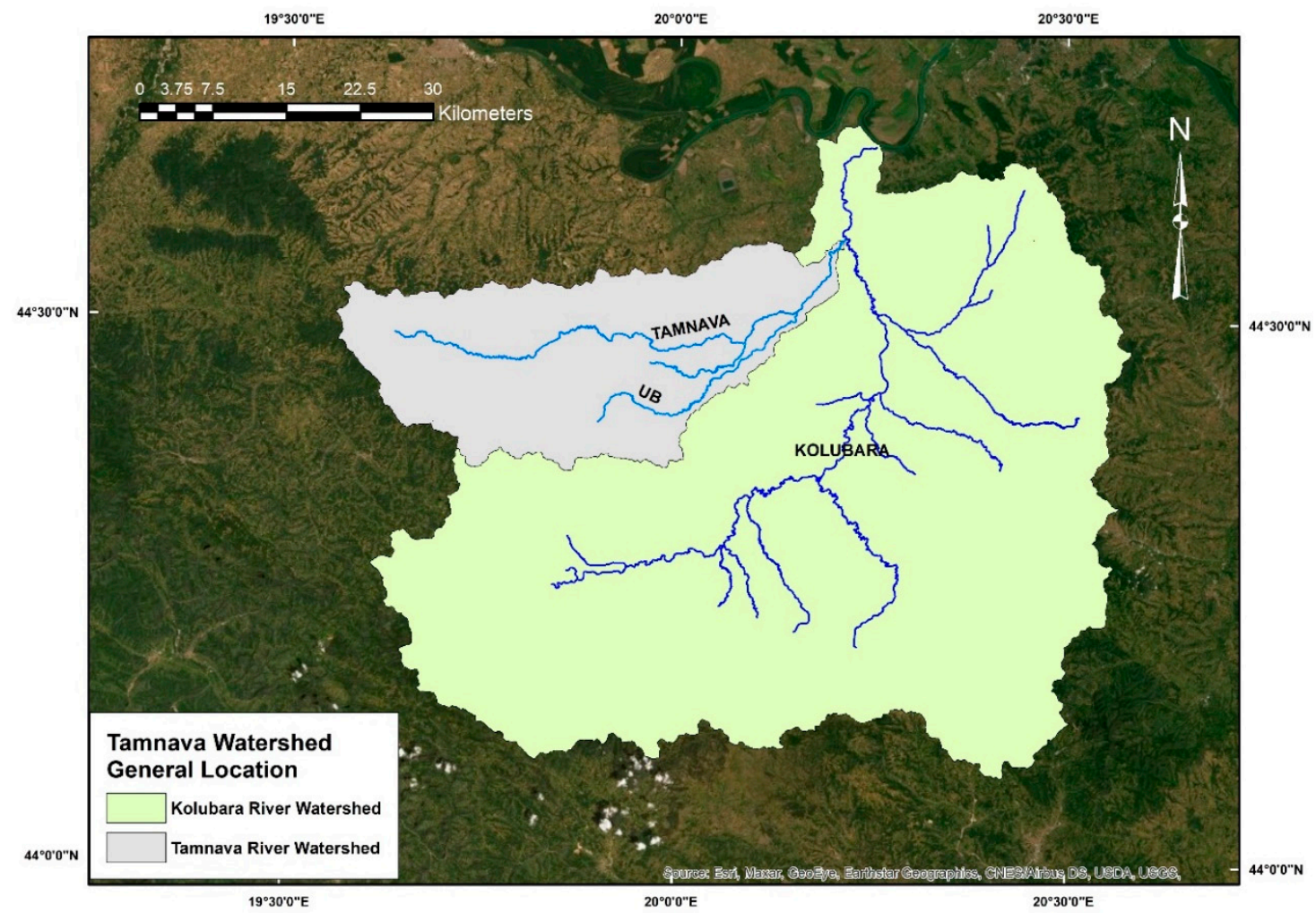

Figure 1. The study area: location of the Kolubara River watershed in Serbia (top) and the subbasin of the Tamnava River (bottom).

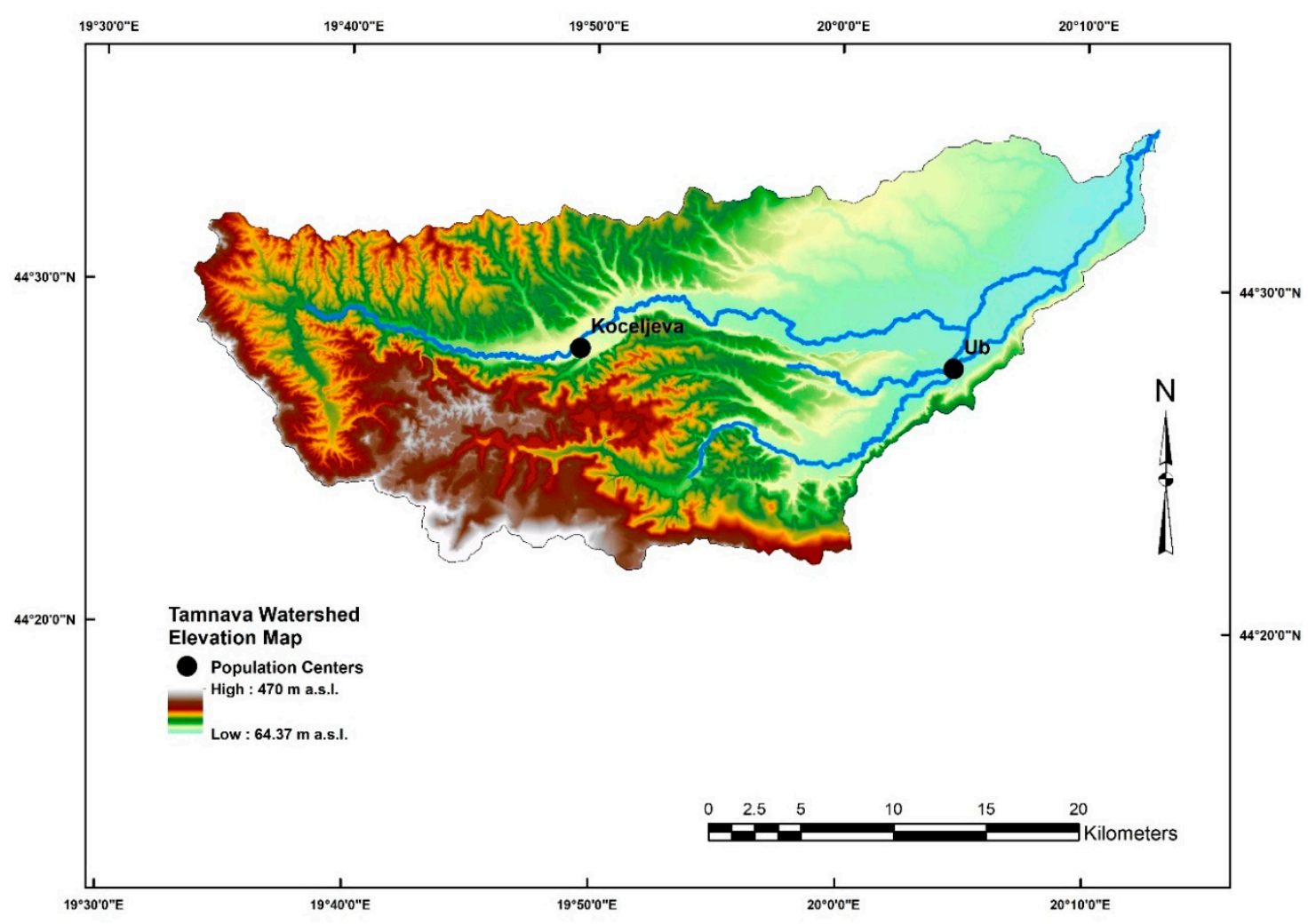

Figure 2. Cont. 


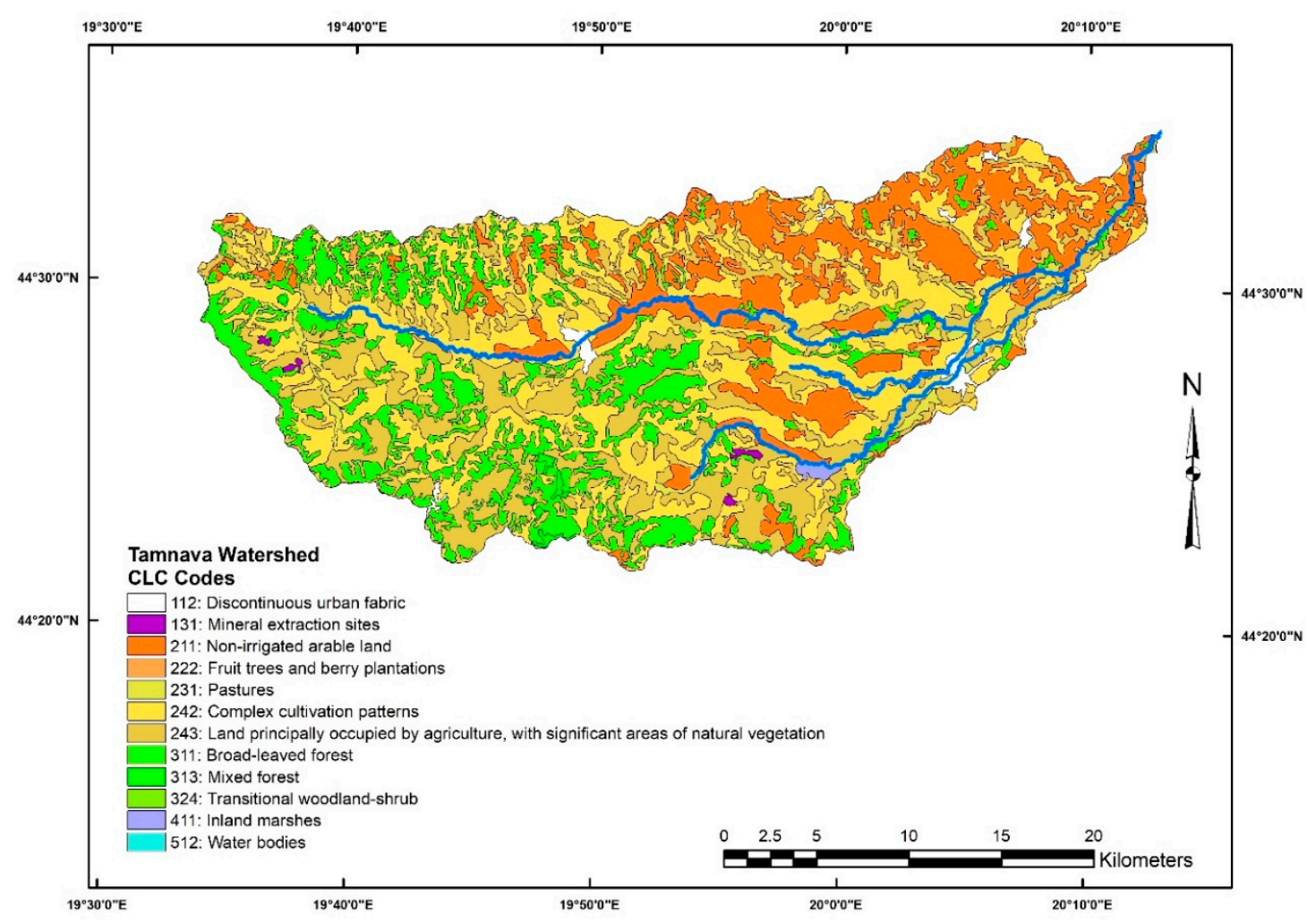

Figure 2. Maps of terrain elevations (top) and land cover (bottom) of the Tamnava River watershed.

Hydroclimatic regime of the Tamnava watershed is characterized by pronounced seasonal pattern, with the highest flows in early spring due to combined rainfall and snowmelt, and in early summer due to high-intensity convective rainfall events. The latter mainly occur in June, which is the month with the greatest precipitation amount. Mean annual precipitation amounts to $787.7 \mathrm{~mm}$, while mean annual temperature is $11.4^{\circ} \mathrm{C}$ for 1981-2010. Mean annual flow of the Tamnava River at Koceljeva is $0.99 \mathrm{~m}^{3} / \mathrm{s}$, and of the $\mathrm{Ub}$ River at the $\mathrm{Ub}$ gauge is $1.01 \mathrm{~m}^{3} / \mathrm{s}$. The highest flows at these gauges are $178 \mathrm{~m}^{3} / \mathrm{s}$ and $146 \mathrm{~m}^{3} / \mathrm{s}$, respectively, and were observed during a great flood in May 2014 .

The study area has been affected by a number of historic flood events $(1999,2006,2009,2020$, and earlier), including the catastrophic flood in May 2014. Flooding in the Tamnava watershed has often been caused by flooding of the river Kolubara, whose high-water levels would prevent efficient drainage from the Tamnava watershed and cause excessive backflow flooding in its interior. Historically, the floods along the Tamnava River have caused considerable damages, particularly in the vicinity of its confluence with the Kolubara River.

The May 2014 flood was an unprecedented event in the hydrological record of the whole West Balkans region [20]. It was triggered by heavy rain falling during several days over near-saturated soils after several similar antecedent events. The extent of flooding exceeded historical records, with the Kolubara watershed being among the most affected ones. High water levels remained in the river valleys for weeks; the damages were substantial, and the casualties were reported.

A special study on the 2014 catastrophic flood [21], herein referred to as the UNDP study, was intended for reconstruction of this flood event and a comprehensive evaluation of various proposed flood mitigation measures in the Kolubara watershed. This extensive study comprises the following:

- A detailed description of the entire Kolubara watershed, including topography, stream network, soil types, geology, and other relevant features of the watershed, such as population, infrastructure, and economy (particularly agriculture and coal mining).

- Thorough analyses of various aspects of flooding in the Kolubara watershed, including descriptions of the major observed floods in the study area. 
- Development of hydrological and hydrodynamic models aimed at reconstruction of the May 2014 flood event.

- Comprehensive analyses of the existing flood protection measures in the watershed.

- Macro-economic damage assessment in the watershed from the May 2014 flood, and for scenarios of the existing and planned flood mitigation measures.

- Proposal for upgrading the flood mitigation measures in the Kolubara watershed, and the evaluation of their effects by means of developed hydrologic and hydrodynamic models.

This research uses the part of the UNDP study related to the Tamnava watershed as the starting point. The hydrodynamic model developed in the UNDP study is also used in this research with necessary adjustments as described in Section 2.3. For the sake of consistency with the UNDP study, we adopted its notation for stream sections (sectors) along the Tamnava, Gračica, and Ub rivers. The sectors are distinct in their prevalent land use in the river valleys and proposed options for reducing flood risk. The short description of the sectors is presented in Table 1, and the sector boundaries corresponding to the areas of maximum potential flooding extent are shown in Figure 3.

Table 1. River sectors in the study area.

\begin{tabular}{ccccc}
\hline Sector & Stream & Area [ha] & General Description & Agricultural Land Use [\%] \\
\hline 7 & Tamnava & 573.20 & Rural & $99.86 \%$ \\
$7^{\prime}$ & Tamnava & 75.28 & Urban & $35.18 \%$ \\
8 & Tamnava & 3184.30 & Rural & $91.22 \%$ \\
9 & Tamnava & 1429.02 & Rural & $92.72 \%$ \\
11 & Ub & 1384.33 & Rural & $85.25 \%$ \\
$11^{\prime}$ & Ub & 103.75 & Urban & $82.07 \%$ \\
$11^{\prime \prime}$ & Ub & 101.16 & Urban & $43.99 \%$ \\
12 & Ub & 859.49 & Rural & $94.28 \%$ \\
13 & Gračica & 173.23 & Rural & $100.00 \%$ \\
$13^{\prime}$ & Gračica & 244.58 & Semi-urban & $71.09 \%$ \\
\hline
\end{tabular}

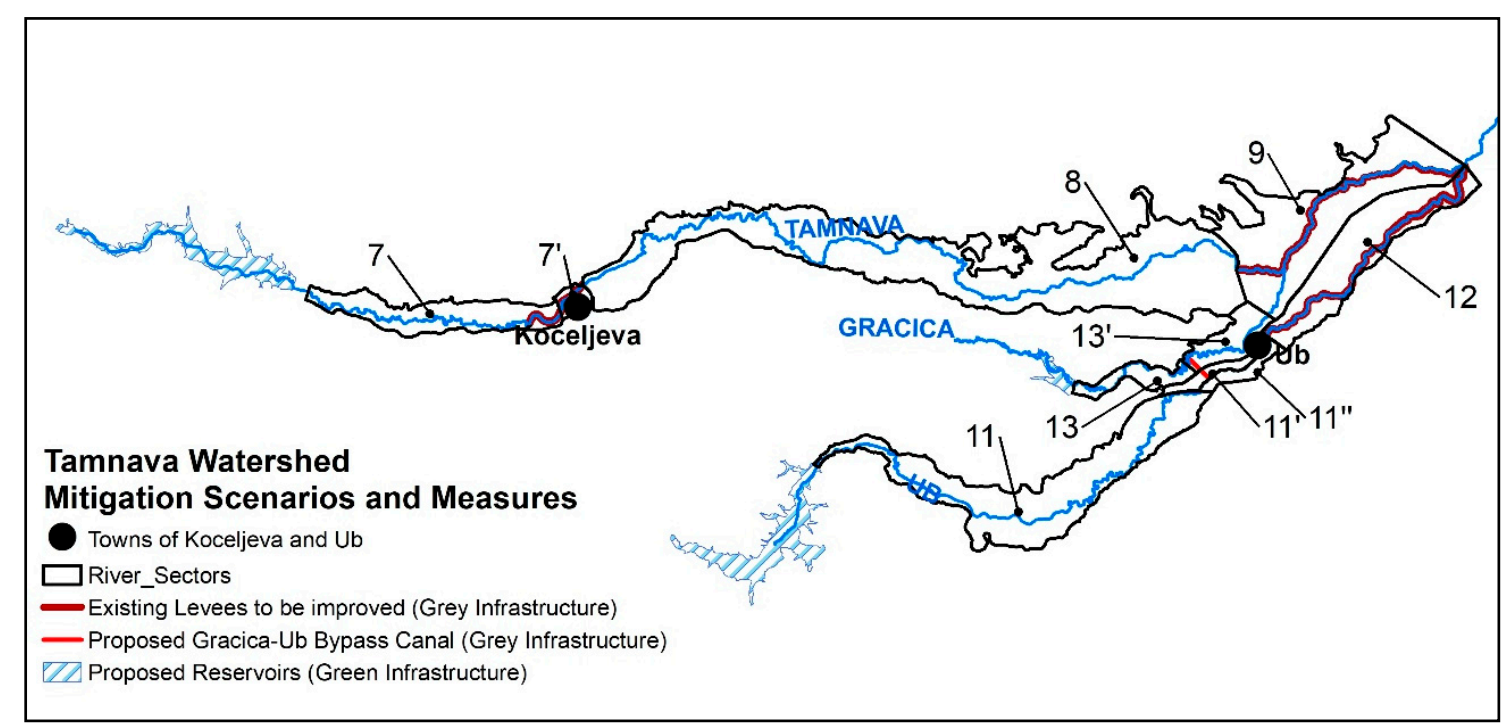

Figure 3. Division of the Tamnava, $\mathrm{Ub}$, and Gračica rivers into river sectors. Figure also shows locations of levees and planned detention basins.

\subsubsection{Flood Mitigation in the Tamnava Watershed}

To reduce flood hazard and consequent damages, the flood protection system in the Tamnava watershed has been set up since 1950s. Flood protection system in 2014, which is the existing system used as reference in this study, is primarily based on the levees along several sections of the Tamnava 
and $\mathrm{Ub}$ rivers (Figure 3). The levees that protect the populated areas along the Tamnava River are designed for 50-year or 100-year floods, while the remaining levees provide protection of agricultural land from 25-year floods.

The mitigation measures that are proposed in the UNDP study [21] and analyzed in this study include:

- Three detention basins with earthen dams at the upper reaches of Tamnava, Gračica, and Ub that should serve as flow regulating and erosion prevention structures during floods and would otherwise retain a minimal amount of water. Considering that detention basins can provide various ecosystem services [22,23], they are considered as green measures in this study. Additionally, natural anti-erosion measures are planned in the UNDP study to complement the detention basins.

- Reinforcement and crown elevation of the existing levees along the Tamnava and $\mathrm{Ub}$, in sectors $7^{\prime}$, 9, and 12, respectively (Figure 3). Additionally, construction of a bypass canal connecting Gračica and $\mathrm{Ub}$ rivers (sector $13^{\prime}$ ) is proposed. All of the above measures are referred to as grey flood protection measures in this study. Locations of the proposed mitigation measures are depicted in Figure 3. The existing levees that already provide certain level of flood protection are planned to be elevated as follows:

Sector $7^{\prime}$, bank protection and levee protecting downtown Koceljeva: increasing flood protection level from return period of 50 years to 100 years;

$\bigcirc \quad$ Sector 9, agricultural levee on both banks of river Tamnava: increasing flood protection level from return period of 50 years to 100 years;

- Sector 12, agricultural levee on both banks of River Ub: increasing flood protection level from return period of 25 years to 100 years.

Technical details of the levee system in the watershed and the proposed detention basins are given in the Supplementary material.

To enable comparison of benefits from implementing green and grey measures, and, consequently, identification of optimal flood protection setup for small, predominately rural watersheds, four alternative scenarios of flood protection in the Tamnava watershed are considered in this study:

1. Baseline scenario (existing conditions, "no action" scenario). This scenario includes only existing flood protection measures and assumes that flood protection level in the watershed would remain the same in the future.

2. Green scenario includes the three proposed detention basins along with the existing grey infrastructure (i.e., levees) with the flood protection level that they currently provide.

3. Grey scenario implies raising the existing levees and constructing the bypass canal, as proposed in the UNDP study.

4. Green-grey scenario includes implementation of both green (detention basins) and grey measures (heightened levees and the bypass canal) in the watershed.

It should be noted that the distinction between green and grey measures is not a clear, straightforward one. Concerning the building material, some elements of green infrastructure (e.g., the dams of the detention basins) may be made of (reinforced) concrete or steel, while the levees (grey measures) are mainly made of local earthen material. In this paper, the distinction between the two groups of measures is not made upon the building material, but rather according to the ecosystem services that the measures can provide. This categorization is in line with the definition provided by European Commission, stating that "green infrastructure provides great benefits for both citizens and biodiversity" [23]. Detention basins can provide habitat for wildlife and keep a fish stock, and their application is deemed to "contribute to meeting the objectives of the 2020 Biodiversity strategy" [23]. In addition, detention basins can offer some recreational opportunities. For the above reasons, the detention basins are considered a green flood mitigation measures in this study, as opposed to the conventional levees and a bypass canal. 


\subsection{Outline of the Methodology}

The methodology for evaluating flood mitigation scenarios presented in this paper is based on assessment of flood risk for each scenario. The flood risk assessment follows a process well elaborated in the literature, with risk being quantified as a product of hazard and vulnerability [24,25], and shown in Figure 4. The flood hazard is here represented by maps of flood depth for different hazard scenarios (i.e., flood return periods or probabilities of exceedance) and different mitigation scenarios. The flood hazard maps are obtained as a result of hydrodynamic modelling of flood flows along the Tamnava, $\mathrm{Ub}$, and Gračica rivers, as described in Section 2.3. Therefore, combining the natural hazard and mitigation scenarios produces multiple scenarios that should assist in identifying the optimal solution for the watershed.

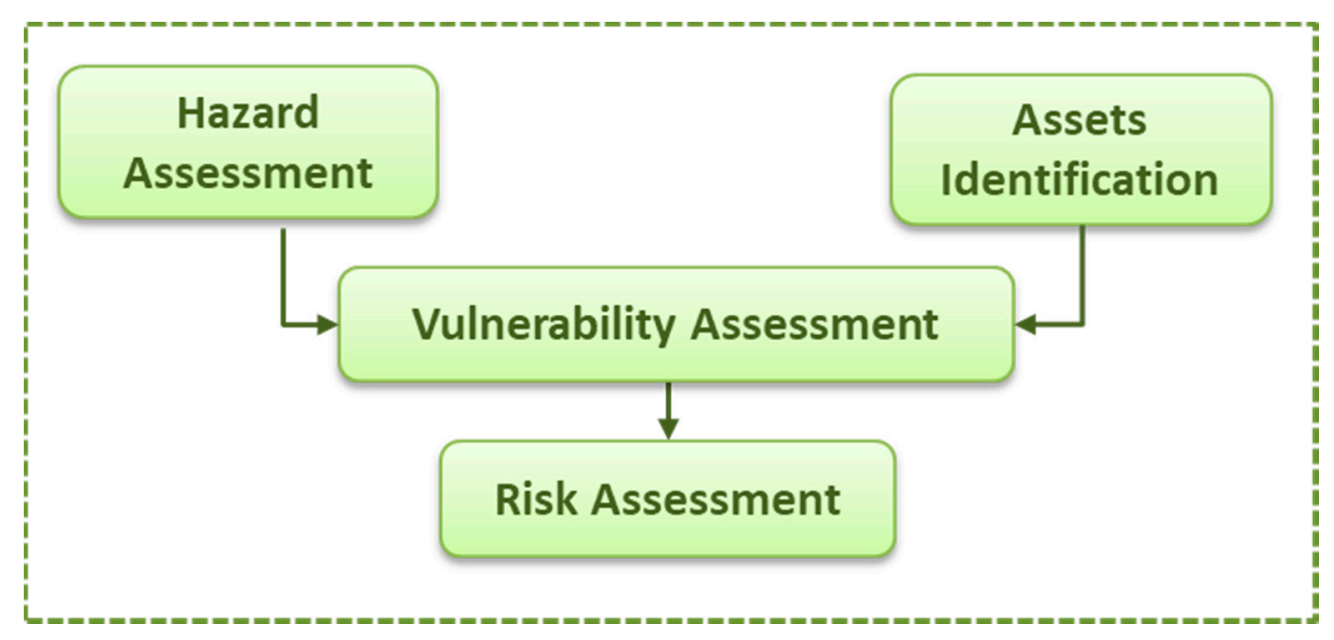

Figure 4. General approach to flood risk assessment for a chosen mitigation strategy.

Assessment of the vulnerability to floods is based on identifying the assets in the focus area that are at risk of flooding. The vulnerability assessment is the basis for flood damage assessment. Vulnerabilities from natural hazards are usually grouped as physical, social, economic, and environmental [26]. However, estimating the potential damages from floods in terms of these four categories can be a complex process associated with high uncertainties. In engineering applications, it is much more common to divide the damages into direct and indirect losses $[17,18]$. In this study, four categories of vulnerabilities, which were identified as the most important ones and for which sufficient data was available, are considered. These include three categories of direct losses and one category of indirect losses:

- Physical damage to the buildings (residential/public).

- Physical damage to building contents and equipment.

- Damage to agricultural crops.

- Population emergency displacement and relocation.

There is an extensive literature on quantifying vulnerability for the considered categories [25,27]. The direct losses are estimated in this study by applying depth-damage relationships, i.e., by calculating the damage in function of the flood depth for each scenario, which is a common approach $[16,28]$ particularly useful for physical assets. The indirect losses of population displacement are estimated on the basis of daily unit costs per person displaced. Details on the vulnerability and damage assessment are given in Section 2.4 . 
Assessment of risk is performed in function of asset vulnerability and damages for a series of synthetic (design) flood events under each mitigation scenario. Additionally, the same methodology for damage assessment is also applied to the flood event of May 2014 and compared to official damage estimates for the selected losses categories to validate the methodology. The effectiveness of a particular mitigation approach under the specified hazard scenario is measured as the damage avoided by implementing that particular option, i.e., as the difference between the losses of the baseline scenario and the considered mitigation scenarios outlined in Section 2.1.2. This step is elaborated in Section 2.5.

\subsection{Hazard Assessment}

The hydrodynamic model used for flood hazard assessment in this paper was originally developed for reconstruction of the extreme flood event in May 2014 in the UNDP study [21], and it will be referred to as MODEL 2014. It is a 1D model specifically developed to simulate all levee breaches and overtopping, and backwater effects that occurred during flood event in May 2014. This model version is calibrated within the UNDP study according to the observed water stages and surveyed flooding extents. An overview of the characteristics of this model and its calibration are presented in the Supplementary material. Details on the reconstruction of this flood event can be found in the literature [29].

The MODEL 2014 was further modified to enable hydrodynamic simulations and flood hazard assessments under different mitigation scenarios described in Section 2.1. For the existing flood protection, levee breaches and overtopping options were excluded from the MODEL 2014. Further modifications of the hydrodynamic model were aimed at simulations under the future mitigation scenarios by including the three proposed detention basins (green scenario), elevated levees, and the bypass canal (grey scenario) and combination of both types of measures (green-grey scenario).

The hydrodynamic models of the Tamnava, $\mathrm{Ub}$, and Gračica rivers were fed with the hydrographs as the upstream boundary conditions, and stages of the Kolubara River at the confluence with Tamnava as the downstream boundary condition [21]. Only MODEL 2014 was used for non-stationary simulations. The hydrographs used to run MODEL 2014 were either observed at the stream gauges or simulated by hydrologic models [29]. The remaining model versions were used for stationary simulations and were driven with design flood flows of various return periods. The approach of using only the peak flows instead of entire hydrographs was adopted as a conservative approach that maximizes the flooding extents and the flood damage.

The design flows for hydrodynamic simulations were estimated in the UNDP study [21] at the locations of the stream gauges in the watershed by applying the flood frequency analyses of the observed annual maximum floods. These design floods were regionalized to estimate corresponding flows at ungauged locations in the watershed that were needed for hydrodynamic simulations.

All hydrodynamic model versions were developed with the HEC-RAS software [30]. The models included all related structures, such as levees, reservoirs, detention ponds, and bridges. Terrain data were obtained by combining several Digital Terrain Models (DTMs) available for the Kolubara watershed. The combined DTM was further refined according to the structural lines, such as the levees and road network, river cross-sections placed at $500 \mathrm{~m}$ distance from additional geodetic surveys, as well as precise data on the bridge structures. The data exchange between HEC-RAS and GIS software was established via the HEC-GeoRAS tool [31].

Simulations with the MODEL 2014 were performed in this paper to enable comparison of losses during the flood event in May 2014 to the official post-disaster estimates of flood damages in the Tamnava watershed, and, thus, to enable validation of the damage assessment approach used in this paper. The other model versions were used for flood hazard and damage assessments under the four analyzed flood mitigation scenarios. Flood hazards were assessed for 2-, 10-, 20-, 50-, 100-, 200- and 1000 -year design floods. In all simulations performed, it was assumed that the protection system fulfills its design role completely (no levee breaches). 


\subsection{Asset Identification and Vulnerability Assessment}

Three principal types of assets, and four corresponding types of vulnerabilities, were identified for the study:

- $\quad$ Building stock and its inventory (contents).

- Agricultural production.

- Population affected by flooding and cost associated with its temporary displacement.

Selection of the vulnerability categories was based on availability of the data, prevalence of assets in the area, and compatibility with categories used in the UNDP study [21] for the purpose of comparison of flood damage estimates.

\subsubsection{Building Stock and Its Inventory}

In this paper, the micro-level flood damage assessment is conducted, meaning that evaluation of vulnerabilities is performed on a level of individual buildings for a series of hazard events. This approach is more detailed in comparison to the aggregated approach applied in the UNDP study [21]. A total of 5984 permanent structures were identified from aerial photogrammetric imagery within the river sectors' boundaries (the maximum potential extent of flooding). The number of structures and their occupational classes were verified in the field. Of these, $63.5 \%$ are residential buildings (primarily single family, low-density and farm houses), $27.8 \%$ are agricultural buildings, $6.4 \%$ are commercial, educational, and government structures, with the remaining $2.3 \%$ being light industrial buildings. The characteristics of the above types of structures (i.e., occupancy classes) are typical for this region and this part of the country [32].

The damages to structures caused by floods are estimated using the depth-damage function (DDF). The damage as a function of water depth in the structure is typically expressed not in absolute monetary values, but as percentage of the "maximum damage value" [33], which is the value of replacing the completely destroyed structure with a new one.

In this paper, the DDFs for residential, commercial, industrial, and transportation occupancy classes of buildings were adopted from the Joint Research Center's global database [33], with modifications applied for Serbia and for inflation. It was conservatively assumed that buildings have no basements. All the modifications applied to DDFs from [33] are made in accordance with field investigations.

The shape of DDF for buildings was also adopted for the corresponding building content. The maximum damage value for the building content ranged between $50 \%$ and $150 \%$ of the maximum damage value for the corresponding building structure, as shown in Table 2. An example of the DDF for residential buildings used in the study is presented in Figure 5.

Table 2. Maximum damage values used in the study.

\begin{tabular}{ccc}
\hline \multirow{2}{*}{ Building Type } & Maximum Damage ${ }^{\mathbf{1}}\left[\mathbf{\epsilon} / \mathbf{m}^{\mathbf{2}}\right]$ \\
\cline { 2 - 3 } & Structure & Content \\
\hline Residential $^{2}$ & $203-271$ & $101-136$ \\
Commercial $^{\text {Industrial }}$ & 298 & 298 \\
Transportation $^{\text {Agricultural }}{ }^{3}$ & 207 & 310 \\
Agri $^{2}$ & 107 & n/a \\
\hline
\end{tabular}

Notes: ${ }^{1}$ Inflation corrections are made to reflect costs for 2020. ${ }^{2}$ For very old buildings, maximum damage for the structure is reduced by $50 \% .{ }^{3}$ Adopted commercial DDFs with reductions for content and structural damage. 


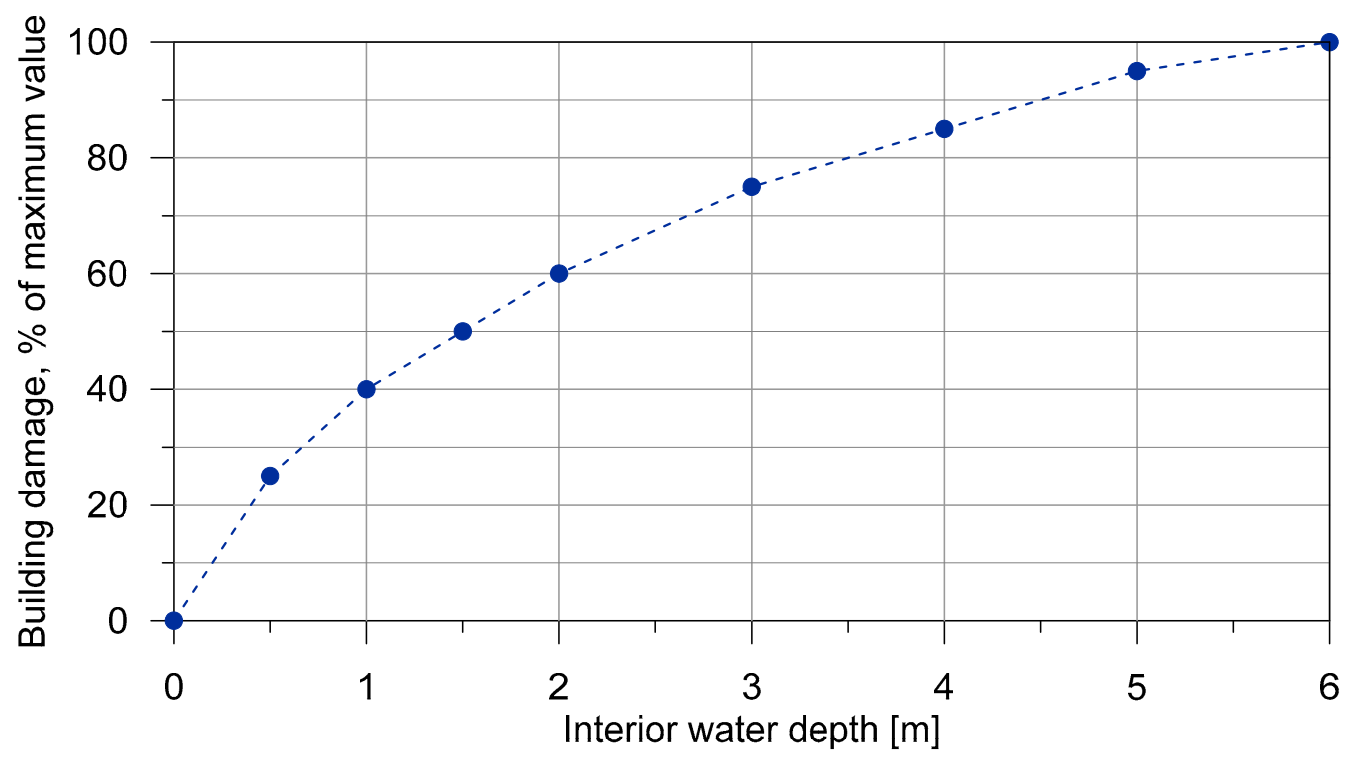

Figure 5. Depth-damage function for residential buildings in the Tamnava watershed.

\subsubsection{Agricultural Production}

Agricultural production and its vulnerability are analyzed through three principal crops productions (corn, potatoes, apples) and unbaled hay [21]. The seasonality of the flood event and resulting various levels of vulnerability of each crop were not taken into account.

The crops were conservatively assumed to have a constant buyout cost and that the production yield would remain unchanged over time. The resulting monetary revenue represents the maximum potential agricultural production losses for any given season. The values for buyout costs and production yields were adopted from the UNDP study and modified for inflation, as presented in Table 3.

Table 3. Agricultural production and maximum potential losses due to flooding, expressed in terms of annual revenue.

\begin{tabular}{ccc}
\hline Culture & Yield [Tonnes/ha] & Annual Revenue [€/ha] \\
\hline Corn & 5.90 & 770 \\
Potatoes & 18.40 & 3851 \\
Apples & 16.90 & 7318 \\
Unbaled hay & 1.60 & 208 \\
\hline
\end{tabular}

The vulnerability of the agricultural resources and crop producing areas was defined as their direct exposure to flooding, regardless of the amount of time spent under water. Damages to crops such as apples and corn are highly dependable on the depth of flooding [34], and have been adjusted accordingly to conform to field observations and high water marks. Potatoes and unbaled hay located within the flood boundaries were considered a total loss, regardless of the corresponding depth of flooding.

\subsubsection{Population Affected by Flooding and Temporarily Displaced}

Population may be affected by flooding in various ways, from having their domiciles directly damaged to being evacuated and displaced due to impeding environmental, structural, infrastructural, or health-related hazards. In this study, only the inhabitants whose residences were directly affected by flooding are considered. The population potentially exposed to flooding within the study area is estimated at 9155 [21], with 3800 residential structures in the same domain and an average number of 2.41 inhabitants per structure. 
The vulnerability of population can be defined through displacement time, i.e., time for residents to be relocated until imminent danger is gone or until the necessary repairs are completed. The displacement duration varies with the depth of interior flooding [35] and is presented in Table 4.

Table 4. Displacement time for flooding in residential structures.

\begin{tabular}{cccccccc}
\hline Depth of flooding [m] & 0.0 & 0.5 & 1.0 & 1.5 & 2.0 & 3.0 & 4.0 \\
\hline Displacement time [days] & 0 & 74 & 148 & 221 & 295 & 443 & 443 \\
\hline
\end{tabular}

The cost of relocation usually includes both the one-time evacuation costs and the expenses related to temporary housing. This study considered only the temporary housing expenses estimated at approximately $10 €$ per person per day [36].

\subsection{Valuation of the Flood Mitigation Scenarios}

The effectiveness of a particular flood mitigation scenario $S$ can be measured by the reduction of flood risk in comparison to the baseline scenario. In other words, the benefits gained by implementing specific set of flood mitigation measures are quantified in terms of avoided damages, i.e., as the difference between flood damage $D_{0}$ estimated without these measures (baseline scenario) and the damage $D_{S}$ with these measures (flood mitigation scenario $S$ ).

The expected annual damage EAD is the common indicator of the flood risk and can be obtained from the probability distribution of the damages [37]. In practice, it is calculated as the sum-product of the damages and their annual probabilities of exceedance:

$$
\mathrm{EAD}=\sum_{i=1}^{M} D_{i} p_{i}
$$

where $M$ is the number of probabilities of flood hazard $p_{i}$ for which the damages $D_{i}$ are evaluated. The expected annual benefit from the mitigation scenario $S$ can then be computed based on all $M$ considered return periods $T_{i}=1 / p_{i}$, and taking into account $L$ loss categories:

$$
\mathrm{EAB}_{S}=\sum_{i=1}^{M} \sum_{j=1}^{L}\left(D_{0, i j}-D_{S, i j}\right) p_{i}
$$

where $\mathrm{EAB}_{S}$ denotes expected annual benefit for flood mitigation scenario $S, D_{0, i j}$ are damages estimated for the baseline scenario (existing flood protection level in the watershed), and $D_{S, i j}$ are damages under flood mitigation scenario $S$. Subscript $j$ indicates loss category, whereas subscript $i$ is related to flood return period. Four different loss categories are considered in this study $(L=4)$.

For the long-term monetary analysis, it is useful to compute the total benefit as the net present value $\mathrm{NPV}_{S}$ from implementing specific flood mitigation scenario $S$ by taking into account discount rate $d$ and planning horizon $N$, as follows:

$$
\mathrm{NPV}_{S}=\sum_{t=1}^{N} \frac{\mathrm{EAB}_{S}}{(1+d)^{t}}
$$

The long-term benefits are calculated for two planning horizons, namely 30 and 50 years, assuming the discount rate of $7 \%$, as in the UNDP study [21].

\section{Results}

The results of the conducted flood loss assessments are complex and are examined from viewpoints of reduction of flood hazard and reduction of flood losses, i.e., the benefits from implementing various 
flood mitigation measures. To evaluate flood loss assessment in this research, the flood losses in flood event in May 2014 are compared to corresponding officially made estimates.

\subsection{Flood Hazard}

The flood hazard maps under the baseline and three alternative flood mitigation scenarios in the Tamnava watershed result from hydrodynamic modelling, as described in Section 2.3, for each considered return period $(2,10,20,50,100,200$, and 1000 years). Table 5 presents peak flows at the locations of the three stream gauges under all the four flood mitigation scenarios, and for all considered return periods.

Table 5. Design flood flows at the Koceljeva, Ćemanov Most, and Ub stream gauges under the four flood mitigations scenarios.

\begin{tabular}{|c|c|c|c|c|}
\hline \multirow{2}{*}{$\begin{array}{l}\text { Return Period } \\
\text { (Years) }\end{array}$} & \multirow{2}{*}{$\begin{array}{l}\text { Flood Mitigation } \\
\text { Scenario }\end{array}$} & \multicolumn{3}{|c|}{ Peak Flood Discharge $\left[\mathrm{m}^{3} / \mathrm{s}\right]$} \\
\hline & & $\begin{array}{l}\text { Tamnava at } \\
\text { Koceljeva }\end{array}$ & $\begin{array}{c}\text { Tamnava at } \\
\text { Ćemanov Most }\end{array}$ & $\mathrm{Ub}$ at $\mathrm{Ub}$ \\
\hline \multirow{4}{*}{2} & Existing & 38.31 & 37.29 & 28.50 \\
\hline & Green & 6.95 & 7.18 & 6.70 \\
\hline & Grey & 38.31 & 37.29 & 28.50 \\
\hline & Green-Grey & 6.95 & 7.18 & 6.70 \\
\hline \multirow{4}{*}{10} & Existing & 69.61 & 67.83 & 72.80 \\
\hline & Green & 18.23 & 20.41 & 15.60 \\
\hline & Grey & 69.61 & 67.83 & 72.80 \\
\hline & Green-Grey & 18.23 & 20.41 & 15.60 \\
\hline \multirow{4}{*}{20} & Existing & 89.09 & 85.91 & 91.90 \\
\hline & Green & 20.00 & 29.65 & 22.40 \\
\hline & Grey & 89.09 & 85.91 & 91.90 \\
\hline & Green-Grey & 20.00 & 29.65 & 22.40 \\
\hline \multirow{4}{*}{50} & Existing & 122.23 & 119.12 & 117.20 \\
\hline & Green & 52.10 & 50.05 & 36.40 \\
\hline & Grey & 122.23 & 119.12 & 117.20 \\
\hline & Green-Grey & 52.10 & 50.05 & 36.40 \\
\hline \multirow{4}{*}{100} & Existing & 171.10 & 182.93 & 130.40 \\
\hline & Green & 76.32 & 74.07 & 52.40 \\
\hline & Grey & 171.10 & 182.93 & 130.40 \\
\hline & Green-Grey & 76.32 & 74.07 & 52.40 \\
\hline \multirow{4}{*}{200} & Existing & 199.76 & 194.08 & 155.40 \\
\hline & Green & 112.59 & 108.67 & 75.50 \\
\hline & Grey & 199.76 & 194.08 & 155.40 \\
\hline & Green-Grey & 112.59 & 108.67 & 75.50 \\
\hline \multirow{4}{*}{1000} & Existing & 311.19 & 320.59 & 203.60 \\
\hline & Green & 271.38 & 259.47 & 176.30 \\
\hline & Grey & 311.19 & 320.59 & 203.60 \\
\hline & Green-Grey & 271.38 & 259.47 & 176.30 \\
\hline
\end{tabular}

The hazard map of the 100-year flood under existing flood protection system is shown in Figure 6. As described in Section 2.1, the existing levees already provide some flood protection level to certain parts of the Tamnava watershed, primarily to those in urban setting (e.g., sectors $7^{\prime}, 11^{\prime}$ and $11^{\prime \prime}$ ). These parts of the watershed have lower flood hazard level under current conditions than the other sectors in the watershed. Flood hazard is particularly pronounced in the most downstream parts of the watershed (e.g., sectors 9 and 12, some parts of sectors 8 and 13; see Figure 6). 


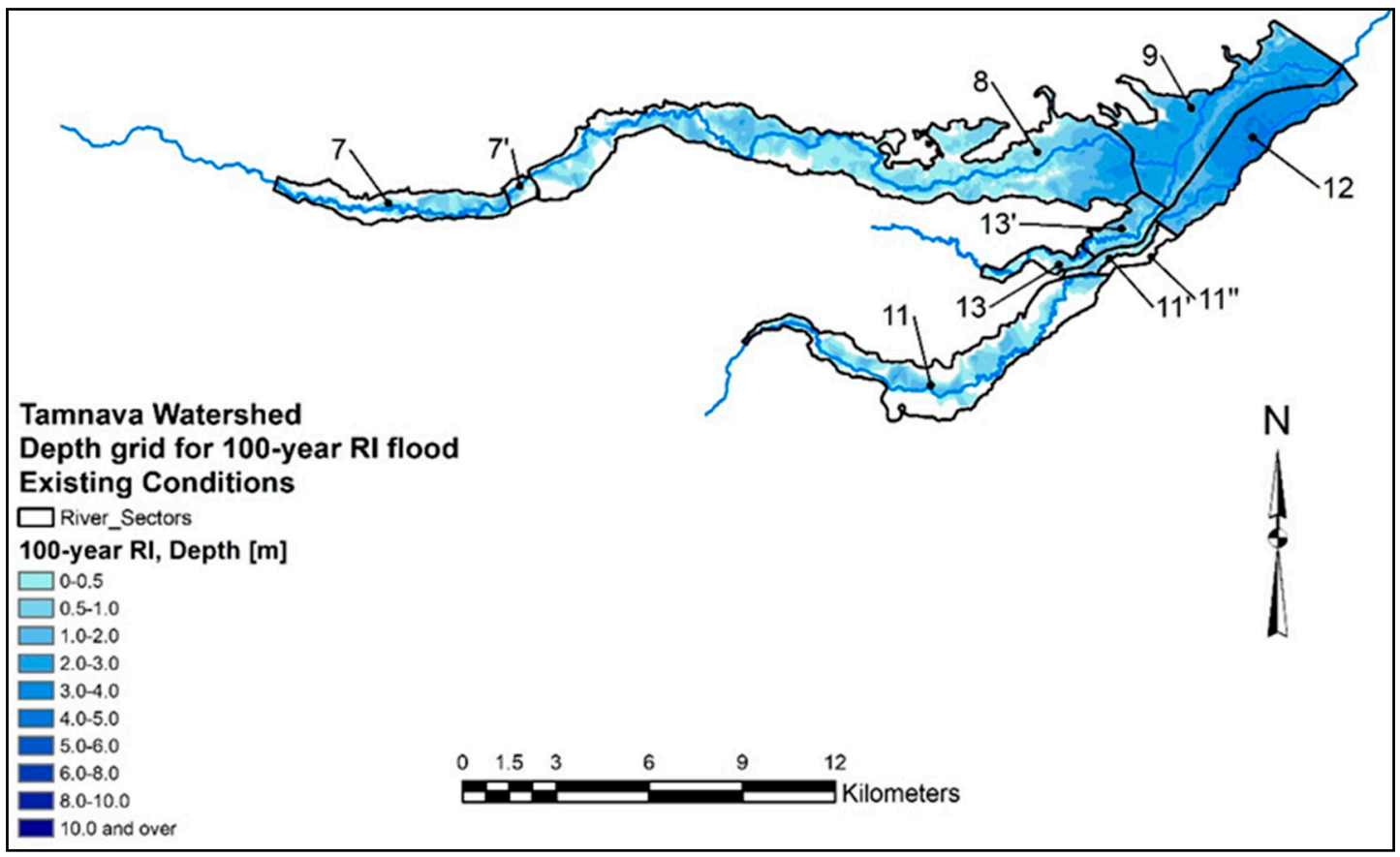

Figure 6. Flood hazard due to 100-year flood in the Tamnava watershed under the baseline scenario (existing flood protection system).

Figure 7 presents the 100-year flood in the Tamnava watershed under the three considered scenarios of flood mitigation development. Their effects can be inferred by comparing these hazard maps to the map in Figure 6. The greatest hazard reduction is obtained under the green-gray scenario. Interesting examples are the most downstream sectors 9 and 12, which are not flooded by the 100-year event under all development scenarios shown in Figure 7. Although the existing levees provide protection from the 25- and 50-year floods (Section 2.1), the detention basins proposed within the green scenario provide sufficient reduction of the 100-year flood, so that it can be conveyed without overtopping in these sectors. These results are obtained also for the 200-year flood, while the 1000-year flood (not shown here) causes levee overtopping in sectors 9 and 12. Reduced flood hazard is also noticed in sector 13', where construction of the bypass canal is planned (see Figure 3). Comparison of the flood hazard maps for different return periods shows that the grey measures have effects in their immediate proximity, while the green measures (i.e., detention basins) reduce peak flows and pertinent flood levels along the downstream river sections, thus having farther-reaching effects.

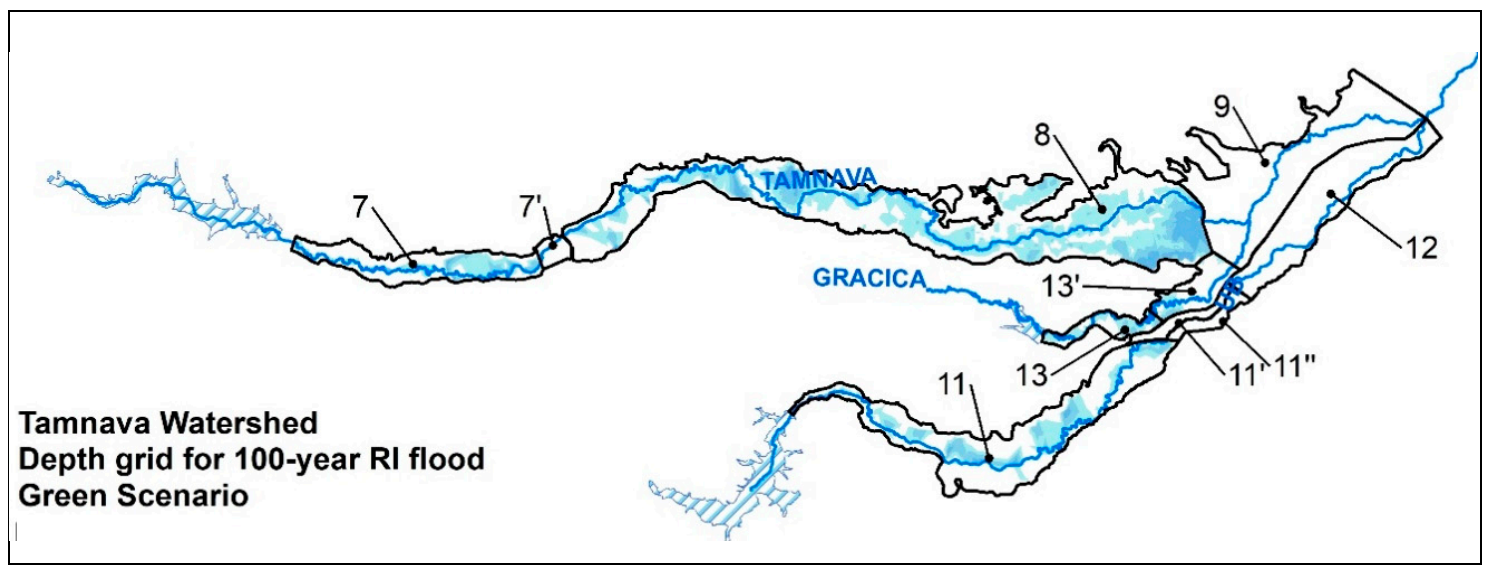

Figure 7. Cont. 


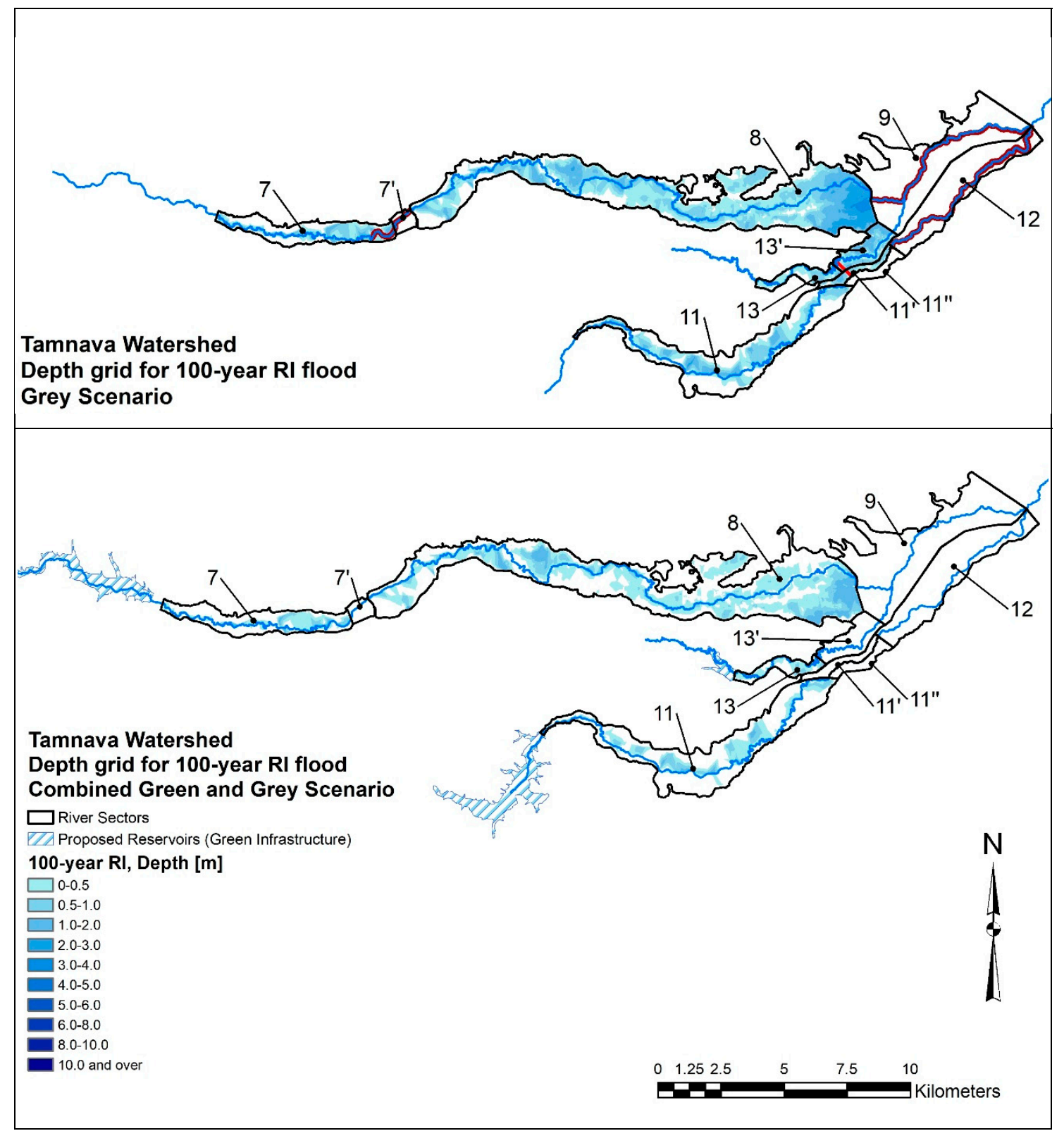

Figure 7. Effects of the three flood mitigation scenarios on flood hazard in the Tamnava watershed: green (top), grey (mid), and combined green-grey (bottom panel). The figure shows hazard due to 100-year flood.

The flood hazard maps enable identification of the affected assets and the depth of flooding water. Figure 8 shows water depth in each building in downtown Ub due to 200-year flood event under baseline and green scenarios and illustrates how the fine-scale asset data and a fine-resolution hazard map facilitate the micro-scale assessment of damages. 

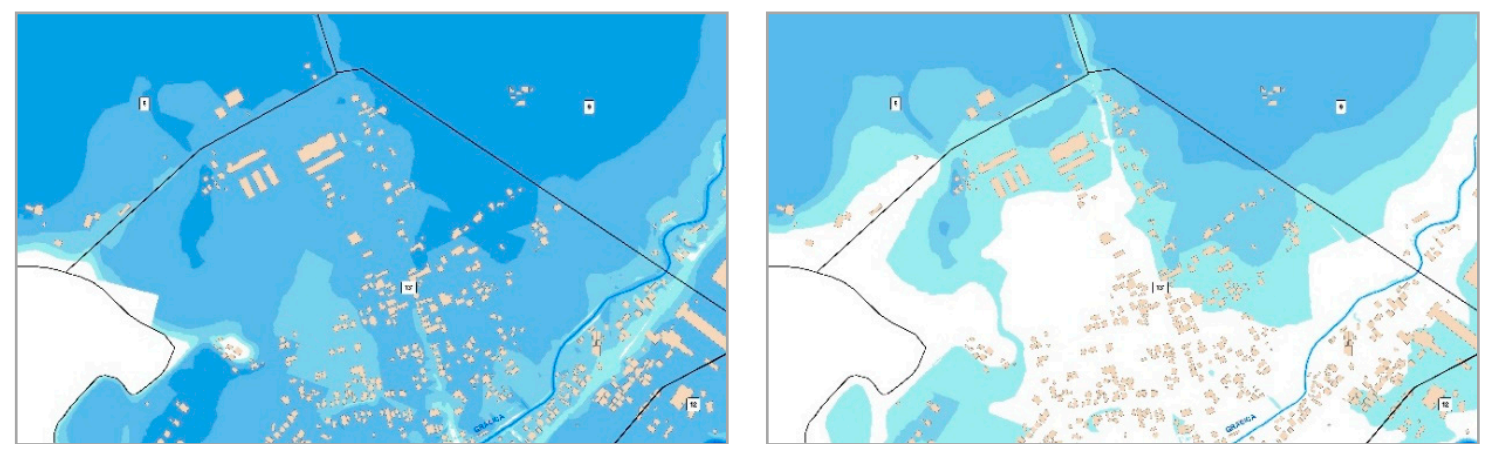

Figure 8. Water depths due to 200-year flood event in downtown $\mathrm{Ub}$, including part of sectors 8, 9, 12, and $13^{\prime}$, under existing flood protection measures (left panel) and under green scenario (right panel).

\subsection{Damage Assessment for the 2014 Flood Event}

The losses from the May 2014 flood are estimated using the damage assessment approach described in Section 2.4 and compared to the corresponding official post-event damage assessments given in the UNDP study [21]. The comparison was possible for two asset categories: combined damages for building structures and content, and agricultural losses (population displacement was not considered in [21]). Difference between the estimated damages to the residential structures in two assessments is only $2.5 \%$ (the estimate of $€ 37,897,822$ in this study largely corresponds to the official post-disaster estimate of $€ 38,869,942)$. The two estimates of damages to crops agree fully $(€ 13,113,716$ in this research vs. official estimate of $€ 13,110,157)$.

These comparisons suggest that flood losses estimated in this paper can be considered valid and can provide reasonably realistic assessments of benefits gained by implementing various flood mitigation measures.

\subsection{Benefits from Different Flood Mitigation Scenarios}

Losses due to floods of different return periods and under different flood mitigation scenarios are computed for each river sector in the Tamnava watershed by summing the losses over the four considered loss categories (building structures and their content, agriculture, and population displacement). The losses for all sectors are presented in Figure 9 in function of the flood return period. The losses under the grey scenario are lesser than for the baseline scenario up to the 100-year return period, which is the design criterion for the elevated levees in the grey scenario. The losses for the green scenario are smaller than the losses for the baseline and grey scenarios for all return periods. Finally, the losses for the green-grey scenario show just a marginal improvement in comparison to the green scenario. Similar graphs of damage distribution are plotted for each sector (not shown in the paper), and although they show somewhat different patterns depending on the relative improvement of protection for a particular sector, they generally show that the green scenario is superior to the grey scenario, while the green-grey scenario is just marginally better than the green scenario. 


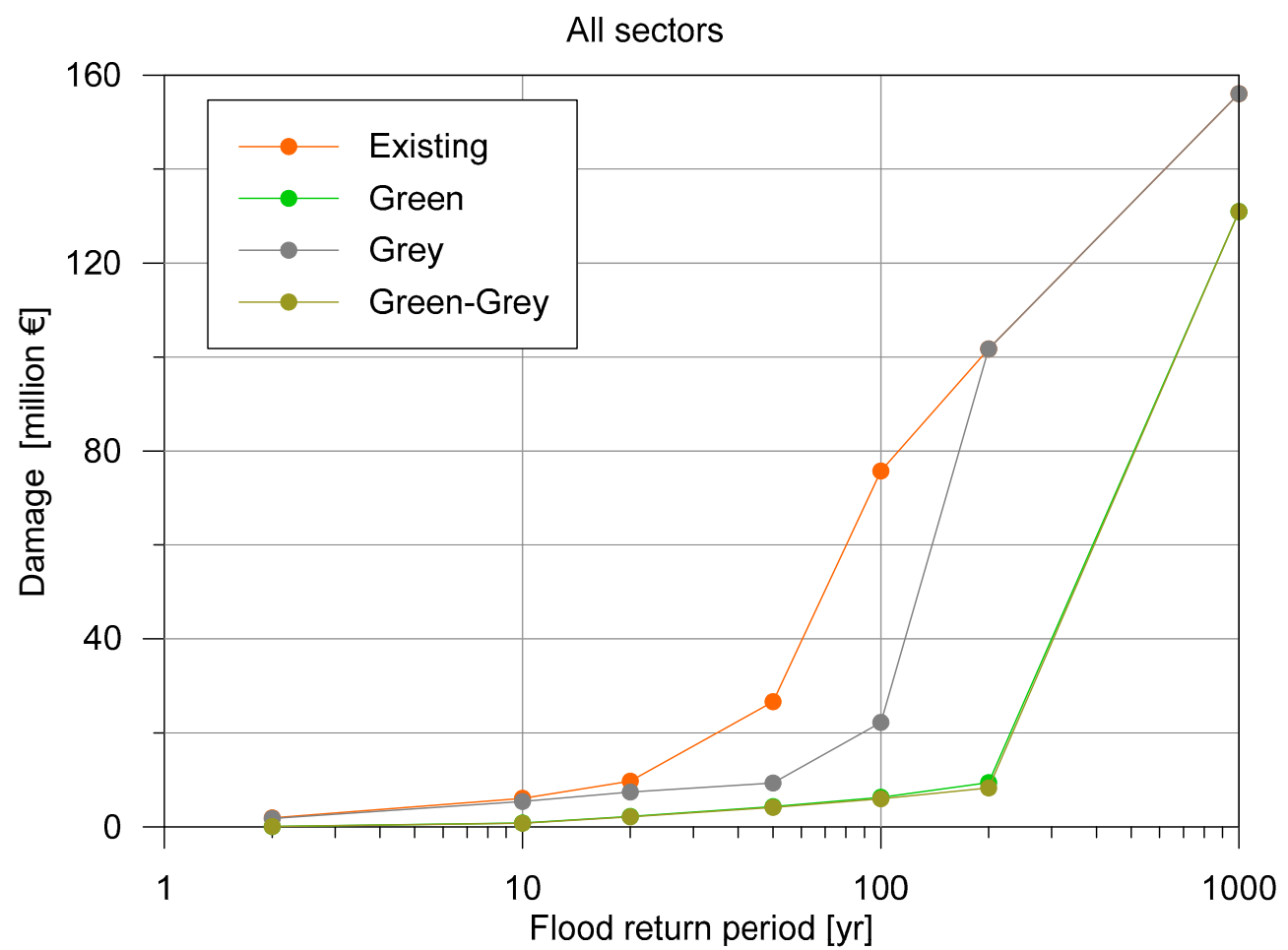

Figure 9. Total flood damages due to flood events of various return periods under the four flood mitigation scenarios in the Tamnava watershed.

The expected annual damages (EAD) for the four scenarios are presented in Table 6, together with their breakdown per loss categories considered. Share of the loss categories in EAD varies across the scenarios. For example, the largest share in EAD have damages to agriculture under all flood mitigation scenarios, except for the existing conditions. Combined losses due to damages to building structures and content are slightly higher than the losses in agricultural production under the baseline scenario. These results can be explained by the fact that Tamnava is predominately rural, agricultural watershed, with low percentage of urbanized and industrial areas. Losses due to displacement of the affected population represent the smallest part of losses due to floods, with up to $5 \%$ of total EADs, and remain relatively constant under all scenarios.

Table 6. Expected annual damages (EADs) and their breakdown per loss category under different flood mitigation scenarios.

\begin{tabular}{cccccc}
\hline \multirow{2}{*}{$\begin{array}{c}\text { Flood Mitigation } \\
\text { Scenario }\end{array}$} & Total & Buildings & Contents & Agriculture & Displacement \\
\cline { 2 - 5 } & \multirow{2}{*}{4.02} & 1.10 & 0.86 & 1.84 & 0.22 \\
Baseline & & $(27 \%)$ & $(21 \%)$ & $(46 \%)$ & $(5 \%)$ \\
& & 0.10 & 0.08 & 0.36 & 0.02 \\
Green & 0.56 & $(17 \%)$ & $(14 \%)$ & $(65 \%)$ & $(4 \%)$ \\
& & 0.61 & 0.48 & 1.67 & 0.13 \\
Grey & 2.89 & $(21 \%)$ & $(17 \%)$ & $(58 \%)$ & $(4 \%)$ \\
& & 0.09 & 0.07 & 0.35 & 0.02 \\
Green-grey & 0.54 & $(17 \%)$ & $(14 \%)$ & $(65 \%)$ & $(4 \%)$ \\
\hline
\end{tabular}


Figure 10 shows EAD for individual river sectors under all flood mitigation scenarios. The greatest losses under the baseline scenario are in sectors $8,9,11$, and $13^{\prime}$, corroborating high flood hazard in these sectors (see Figure 6). In addition, these sectors are characterized by large areas (e.g., sector 8 ) or by presence of urbanized or industrial zones (e.g., sector $13^{\prime}$, see Table 1 ). Sectors 8,11 , and 13 are not covered by grey measures, so EAD for the grey scenario is the same as for the existing conditions. Figure 10 also shows that measures of the green and green-grey scenarios result in lower damages than under grey measures, especially in the most downstream sectors 9 and 12. Under the grey scenario, the heightened levees in these sectors provide protection from the 100-year flood, so the EAD is the result of levee overtopping by more extreme events (200- and 1000-year floods). On the other hand, the detention basins in the green and green-grey scenarios efficiently reduce damages due to such extreme flood events in these sectors, and consequently result in lower EAD than under the grey scenario.

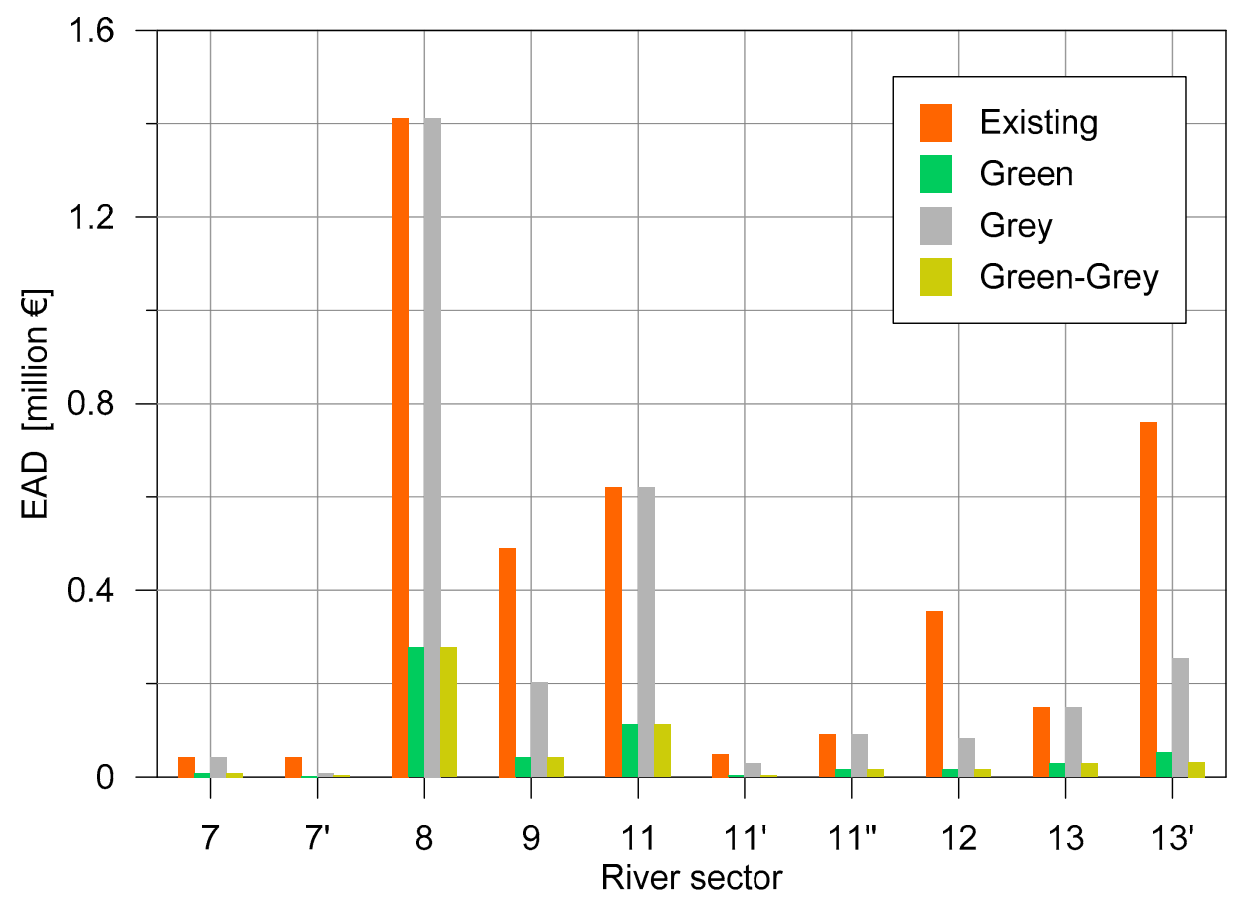

Figure 10. Expected annual damages (EAD) under different flood mitigation scenarios in different river sections across the Tamnava watershed.

As can be seen in Figures 9 and 10, the greatest benefits, i.e., reduction of losses relative to the baseline scenario, are obtained under the green and green-grey scenarios. Figure 11 shows the benefits for different return periods and indicates that the grey scenario has lower benefits than the remaining two scenarios for floods of 100-year return period and smaller. For more extreme floods, there are no benefits under the grey scenario, what is in accordance with designed heightening of the levees to the 100-year protection level. 


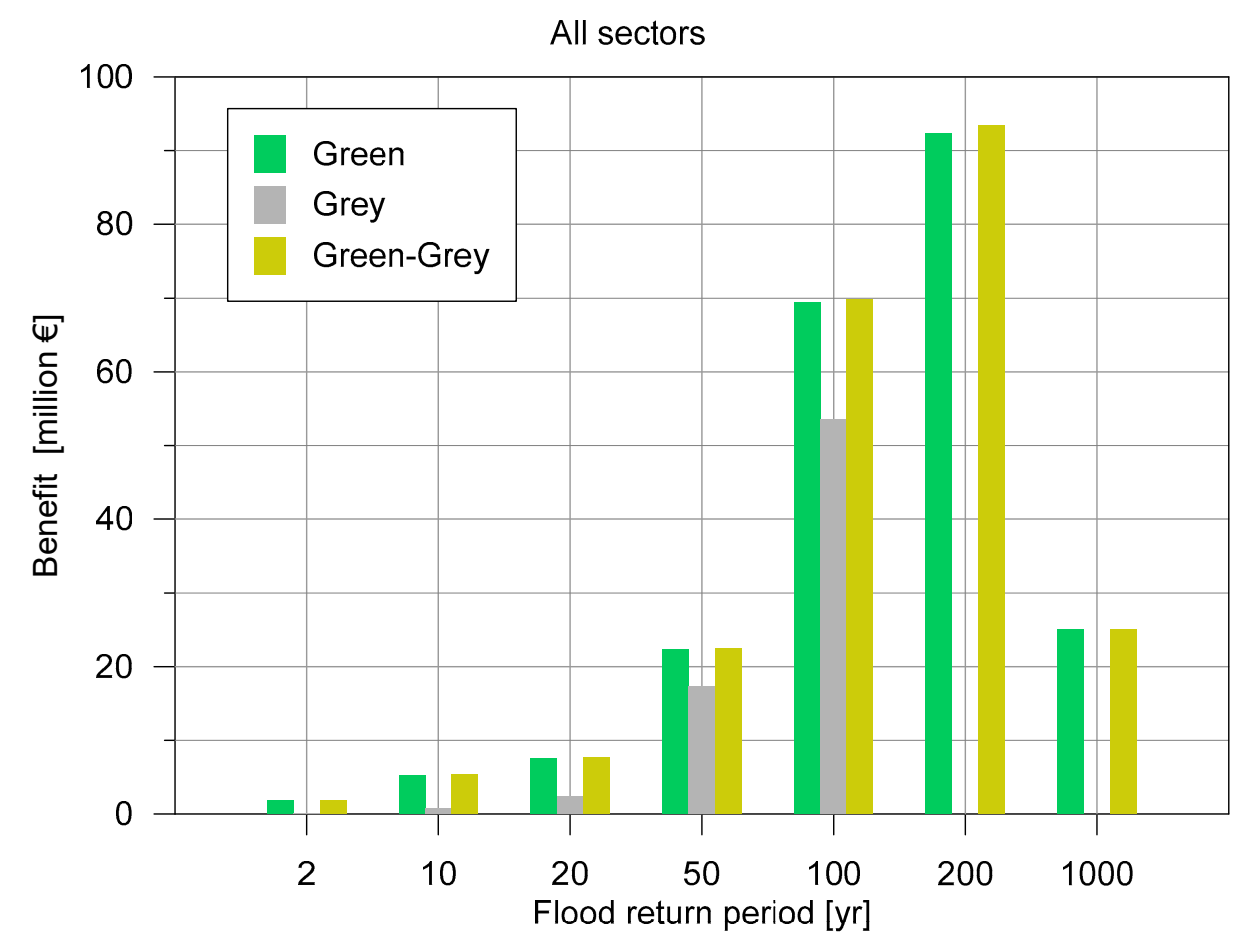

Figure 11. Benefits (loss reduction relative to baseline scenario) in the Tamnava watershed under the three proposed flood mitigation scenarios depending on the flood return period.

Table 7 presents the expected annual benefits (EAB, Section 2.5) for the considered scenarios. This table also suggests that the greatest benefits are obtained under the green and green-grey scenarios, which include detention basins that generally have greater effects on reduction of flood hazard and losses than the levees. Hence, the benefits from implementing measures within the grey scenario are considerably smaller, and reflect primarily in reduction of losses to building structures and contents. This can be explained by the fact that the levees in the grey scenario are intended for protection of populated areas in which the buildings represent the most valuable assets. Since the levees make local impact on flood hazard and loss mitigation, reduction in the remaining, more remote, agricultural parts of the watershed are substantially smaller compared to the other two scenarios. The costs of population temporary displacement are considerably lower than the losses in other categories considered, and this pattern is also exhibited in the benefits. Difference in the benefits between the green and green-grey scenarios is minor. This is because the detention basins reduce flood peaks efficiently in the downstream sections so that there is no overtopping of the existing systems of levees. In other words, the levee heightening included in the green-grey scenario has minor effect in combination with implementation of the detention basins.

Table 7. Expected annual benefits (EABs) under three flood mitigation development scenarios and their breakdown per loss category.

\begin{tabular}{cccccc}
\hline \multirow{2}{*}{$\begin{array}{c}\text { Flood Mitigation } \\
\text { Scenario }\end{array}$} & Total & Building & Contents & Agriculture & Displacement \\
\cline { 2 - 5 } & \multirow{2}{*}{ Green } & 1.00 & 0.78 & 1.47 & 0.20 \\
& \multirow{2}{*}{ Grey } & $(29 \%)$ & $(23 \%)$ & $(43 \%)$ & $(6 \%)$ \\
\hline \multirow{2}{*}{ Green-grey } & \multirow{2}{*}{1.12} & 0.49 & 0.38 & 0.17 & 0.09 \\
& \multirow{2}{*}{3.47} & $(43 \%)$ & $(34 \%)$ & $(15 \%)$ & $(8 \%)$ \\
\hline
\end{tabular}


The benefits achieved by implementing green, grey, and green-grey measures, computed relative to the baseline scenario are also presented for each sector in Table 8 in terms of benefits over the 50-year planning horizon (NPV), and illustrated in Figure 12 in terms of EAB. Four river sectors $(7,8,11,13)$ are not protected by the levees, nor would be under the grey scenario, so there are no benefits under this scenario in these sections. There are also no benefits for sector $11^{\prime \prime}$, which is already protected up to the 100-year flood and would not be additionally protected in the grey scenario. The benefits under the green and green-grey scenarios are the same in all sections, except for section $13^{\prime}$, where the bypass canal is proposed (see Figure 3). As already discussed, levee heightening is not so beneficial if detention basins are implemented in the watershed.

Table 8. Benefits due to implementing flood protection measures under different scenarios, relative to the baseline one (existing flood protection measures) over 50-year planning horizon in each river section and in the entire watershed.

\begin{tabular}{|c|c|c|c|c|c|c|}
\hline \multirow{3}{*}{ Sector } & \multirow{3}{*}{$\begin{array}{c}\text { General } \\
\text { Description }\end{array}$} & \multirow{3}{*}{$\begin{array}{c}\text { Grey } \\
\text { Measures }\end{array}$} & \multicolumn{4}{|c|}{ 50-Year Planning Horizon } \\
\hline & & & \multirow{2}{*}{$\begin{array}{l}\text { NPV, Baseline } \\
\text { Scenario } \\
\text { [€ Million] }\end{array}$} & \multicolumn{3}{|c|}{ Benefits [\% of NPV, Baseline] } \\
\hline & & & & $\begin{array}{c}\text { Green } \\
\text { Scenario }\end{array}$ & $\begin{array}{c}\text { Grey } \\
\text { Scenario }\end{array}$ & $\begin{array}{c}\text { Green-Grey } \\
\text { Scenario }\end{array}$ \\
\hline 7 & Rural & No & 0.589 & $79 \%$ & $0 \%$ & $79 \%$ \\
\hline $7^{\prime}$ & Urban & Yes & 0.593 & $94 \%$ & $81 \%$ & $94 \%$ \\
\hline 8 & Rural & No & 19.50 & $80 \%$ & $0 \%$ & $80 \%$ \\
\hline 9 & Rural & Yes & 6. 77 & $91 \%$ & $59 \%$ & $91 \%$ \\
\hline 11 & Rural & No & 8.57 & $82 \%$ & $0 \%$ & $82 \%$ \\
\hline $11^{\prime}$ & Urban & Yes & 0.684 & $93 \%$ & $41 \%$ & $93 \%$ \\
\hline $11^{\prime \prime}$ & Urban & No & 1.27 & $83 \%$ & $0 \%$ & $83 \%$ \\
\hline 12 & Rural & Yes & 4.90 & $95 \%$ & $77 \%$ & $95 \%$ \\
\hline 13 & Rural & No & 2.05 & $81 \%$ & $0 \%$ & $81 \%$ \\
\hline $13^{\prime}$ & Semi-urban & Yes & 10.49 & $93 \%$ & $67 \%$ & $96 \%$ \\
\hline \multicolumn{3}{|c|}{ The Tamnava watershed } & 55.41 & $86 \%$ & $28 \%$ & $86.5 \%$ \\
\hline
\end{tabular}
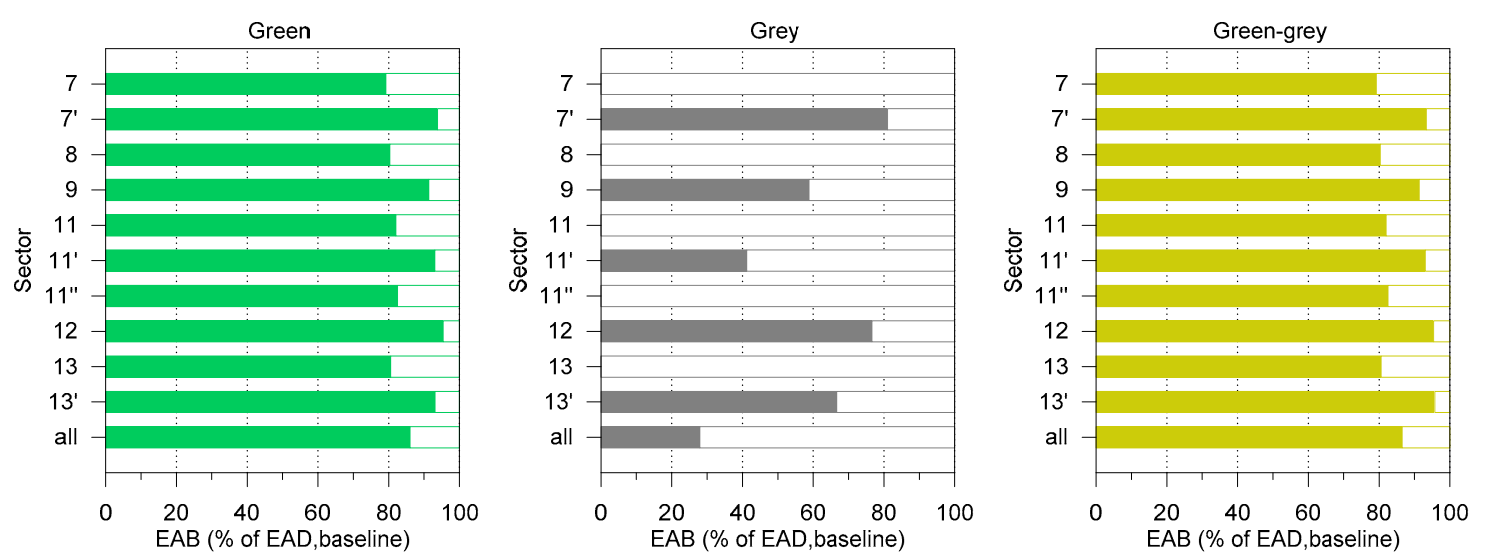

Figure 12. Expected annual benefits EAB, expressed relative to the expected annual damages EAD under the baseline scenario, from implementing different flood mitigation measures in different river sections and in the entire Tamnava watershed.

\section{Discussion}

The presented methodology for finding an optimal flood mitigation setup for small rural watersheds is based on a comprehensive economic evaluation of flood losses under different flood mitigation scenarios. This was a challenging task because the results and experiences from other studies, especially on flood damage estimation, cannot be readily transferred and applied to other regions [38]. Most of the existing research on flood damages is focused on urban areas, and less so on rural agricultural areas. For example, methodologies for estimating damages in buildings are much 
more developed than for other assets (e.g., [39]). Considering that floods cause the greatest losses to crops globally compared to other natural hazards [40], a need emerges for extensive research on flood damage and risk assessment in rural, agricultural watersheds.

Flood hazard assessment under current conditions in the Tamnava watershed shows that the existing levee system already provides some level of flood protection, primarily in the populated areas where the highest-value assets are located. The proposed mitigation measures under green and green-grey scenarios provide the greatest reduction in flood hazard and, consequently, in flood losses in the agricultural areas that presently have no flood protection, such as in sectors 7,8 , and 13 . Although the share of agricultural damages in total losses depends on local conditions in the watershed [34] and prevalence of higher-value crops [41], the results presented here clearly indicate that the agricultural damages are not marginal and have a critical impact on the selection of flood protection development scenarios in predominately agricultural watershed.

Estimation of flood losses in this research is accompanied by inherent uncertainties in both flood hazard and damage assessments, as also demonstrated in many previous studies $[18,38,42]$. Specifically, flood hazard assessment under grey and green-grey scenario is estimated assuming that grey systems (levees and the bypass canal) fulfill their design role, and that there is no flooding of the interior areas. To accurately estimate the flood hazard, a more robust, potentially 2D hydrodynamic model capable of simulating backwater or some interior area flooding could be utilized. Although previous research shows that enhanced hydrodynamic modelling of flood hazard does not substantially reduce uncertainties in damage assessments [43], there is also evidence that flood damages occur outside of the delineated floodplain boundaries corresponding to certain flood return periods [44]. This is important for agricultural watersheds considering that the damages of this type are generally related to large areas and could be affected significantly by the flooding extent.

Uncertainties in the damage assessment can be generated by multiple causes, including vulnerability categories taken into account, spatial scale of the damage model, depth-damage relationships, and estimated asset values (e.g., [38]). In terms of the vulnerability assessment, this research can be characterized as the "lower boundary" analysis because it includes a limited number of key categories. For example, taking other crop cultures into account could increase agricultural losses [41]. Some of the additional categories that could be considered include transportation and energy infrastructure damages and loss of functionality, traffic delays, loss of critical facilities (water and wastewater systems, hospitals, communications, emergency service), lost productivity, business displacement, etc. [17]. More vulnerability categories could be taken into consideration if the adequate data were available, resulting in a more comprehensive flood loss estimates. Alternatively, using rough estimates or generalized (aggregated) data would lead to uncertain damage assessment, as shown by [45]. This is the reason for applying the "lower boundary" assessment approach in this study. If a particular scenario can be proven to be effective with the limited number of vulnerability categories, then it would be even more advantageous if the benefits from additional categories were included. Furthermore, including categories such as ecosystem services offered by green measures would also contribute to higher effectiveness of green mitigation scenarios. Despite the limited choice of vulnerability categories, the proposed flood mitigation scenarios for the Tamnava watershed are compared in relative terms, allowing their unbiased ranking.

In this paper, a comprehensive micro-scale flood damage assessment is applied, with locally adjusted depth-damage relationships and locally estimated asset values. Previous research has shown that the micro-scale approach yields realistic damage estimates [46], and has also recommended that the asset values are adjusted to the regional economic situation and property characteristics [38].

Validation of the damage models is not a usual practice in their development [42,47]. In this paper, the damage assessment approach in this paper is validated successfully for the case of the flood event in May 2014, leading to a conclusion that the approach yields plausible damage estimates. Therefore, it is expected that the uncertainties in flood hazard and limited number of vulnerability categories do not reflect the overall ranking of the scenarios. 
In this study, the effects of the detention basins on peak flow reduction provide a significant advantage for the green and green-grey scenarios. This is expected because the detention basins with considerable storage volume have a principal role in reducing peak flows. The same effects in terms of flood risk reduction would be possible with a grey detention basin of similar storage volume. However, the advantage of a green detention basin should be corroborated by its ecosystem services, the value of which should be included in the assessment of benefits of a flood mitigation scenario [13]. In our case study, the green-grey scenario provides slightly greater loss reduction than the green one. This difference may not suffice to provide its advantage over the pure green scenario if the construction cost of additional grey measures is high. Therefore, for identification of an optimal flood protection development scenario, a comprehensive cost-benefit analysis needs to be performed taking into account environmental, social, and other benefits beside the economic ones [13].

The comparison of the four flood mitigation scenarios in this paper suggests that maintaining the existing flood protection system and complementing it with larger scale green measures intended for reducing flood flows could be an optimal flood protection setup for predominately agricultural watersheds. Further research is needed to perform a sensitivity analysis of the selected flood mitigation scenario to all input data, including terrain information, hydrodynamic models, and various loss categories. The findings of this research are to be tested in different watersheds and for various flood mitigation scenarios that would include a wide variety of measures with special emphasis on green, nature-based solutions. Finally, flood protection based on such solutions is important for wider and sustainable development of the rural areas [48].

\section{Conclusions}

This paper presents a comprehensive, micro-scale flood damage assessment under various scenarios of flood mitigation in a predominately rural, agricultural watershed. The objective of this research is identification of optimal flood protection setup that would result in maximum benefits, i.e., reduction of losses due to floods in such watersheds. Considering a relatively small body of research on this topic up to date, especially on valuation of damages to agricultural assets [41], and considering impacts that flood mitigation in rural watersheds can have on downstream urban areas [34], this paper presents an effort to fill this gap and provide a contribution to a better understanding of flood risk assessment and management in general.

It is demonstrated that the detention basins, as an example of green flood mitigation measures that reduce peak flood flows in downstream river sections, can significantly decrease flood hazard in rural, agricultural watersheds. In the case of the Tamnava watershed, this peak flow reduction is sufficient to enable the existing system of protection levees to operate without failure and accept design floods without overtopping. On the other hand, heightening of levees, as an example of grey flood protection measures, increases flood protection locally, but with the potential of transferring some of the flood hazard further downstream. Unlike urban watersheds, in which high-priced assets are localized in relatively small areas, rural watersheds are characterized by larger areas and long river banks that would require long and excessively expensive levee systems. Additionally, since the crops are the most valuable assets in rural watersheds, flood losses to agriculture represent a great portion of total losses in such areas, as demonstrated by a fine-scale detailed damage assessment in this paper. Therefore, with the assets distributed across large areas in rural watersheds with significantly lower asset values per unit area than in urbanized watersheds, grey flood protection measures such as the levees cannot be as effective in reducing flood risk as the green measures reducing peak flows in rural watershed, as shown in this research.

This paper confirmed that hybrid-type flood mitigation setups, i.e., combining large-scale, far-reaching green mitigation solutions that reduce peak flood flows with the existing smaller scale grey flood protection measures, can be the most effective solution for rural watersheds with prevalent agricultural land use and production. 
Supplementary Materials: The following are available online at http://www.mdpi.com/2076-3417/10/19/6913/s1.

Author Contributions: Conceptualization, R.P. and J.P.; methodology, R.P., J.P. and A.T.; software, R.P.; validation, J.P., A.T.; formal analysis, data curation, R.P.; investigation, R.P., J.P. and A.T.; writing—original draft preparation, R.P.; writing - review and editing, R.P., J.P. and A.T.; visualization, R.P., J.P.; supervision, J.P.; project administration, J.P. All authors have read and agreed to the published version of the manuscript.

Funding: This research was funded by University of Belgrade - Faculty of Civil Engineering as a part of a PhD research activities. Data collection was funded from the European Union's Horizon 2020 Research and Innovation programme under grant agreement No 776866 for the RECONECT (Regenerating ECOsystems with Nature-based solutions for hydro-meteorological risk rEduCTion) project. The study reflects only the authors' view and the European Union is not liable for any use that may be made of the information contained herein.

Acknowledgments: The authors would like to thank the staff of Public Water Management Company "Srbijavode", Belgrade, Serbia, for providing various documentation and information and for their assistance with field visits. Thanks are also due to the staff of the "Jaroslav Černi" Institute, Belgrade, Serbia, for providing the data and modelling results. R.P. is also grateful to Marko Ivetić for his support in the early phase of the research and to Jelena Kovačević Majkić for her assistance in digitizing data. This work was partly supported by the Ministry of Education, Science and Technological Development of Serbia, grant TR37010.

Conflicts of Interest: The authors declare no conflict of interest.

\section{References}

1. Jonkman, S.N.; Brinkhuis-Jak, M.; Kok, M. Cost benefit analysis and flood damage mitigation in the Netherlands. Heron 2004, 49, 95-111.

2. Collentine, D.; Futter, M.N. Realising the potential of natural water retention measures in catchment flood management: Trade-offs and matching interests. J. Flood Risk Manag. 2018, 11, 76-84. [CrossRef]

3. Depietri, Y.; McPhearson, T. Integrating the Grey, Green, and Blue in Cities: Nature-Based Solutions for Climate Change Adaptation and Risk Reduction. In Nature-Based Solutions to Climate Change Adaptation in Urban Areas; Kabisch, N., Korn, H., Stadler, J., Bonn, A., Eds.; Springer Open: Berlin/Heidelberg, Germany, 2017; pp. 91-109.

4. Ruangpan, L.; Vojinovic, Z.; di Sabatino, S.; Leo, L.S.; Capobianco, V.; Oen, A.M.P.; McClain, M.E.; Lopez-Gunn, E. Nature-based solutions for hydro-meteorological risk reduction: A state-of-the-art review of the research area. Nat. Hazards Earth Syst. Sci. 2020, 20, 243-270. [CrossRef]

5. European Environment Agency. Exploring Nature-based Solutions: The Role of Green Infrastructure in Mitigating the Impacts of Weather- and Climate Change-Related Natural Hazards; European Environment Agency: Copenhagen, Denmark, 2015.

6. Ristic, R.; Radic, B.; Miljanovic, V.; Trivan, G.; Ljujic, M.; Letic, L.; Savic, R. "Blue-green” corridors as a tool for mitigation of natural hazards and restoration of urbanized areas: A case study of Belgrade city. Spatium 2013, 18-22. [CrossRef]

7. Rozos, E.; Makropoulos, C.; Maksimović, Č. Rethinking urban areas: An example of an integrated blue-green approach. Water Supply 2013, 13, 1534-1542. [CrossRef]

8. Schubert, J.E.; Burns, M.J.; Fletcher, T.D.; Sanders, B.F. A framework for the case-specific assessment of Green Infrastructure in mitigating urban flood hazards. Adv. Water Resour. 2017, 108, 55-68. [CrossRef]

9. Martínez, C.; Sanchez, A.; Galindo, R.; Mulugeta, A.; Vojinovic, Z.; Galvis, A. Configuring Green Infrastructure for Urban Runoff and Pollutant Reduction Using an Optimal Number of Units. Water 2018, 10, 1528. [CrossRef]

10. Kuller, M.; Bach, P.M.; Roberts, S.; Browne, D.; Deletic, A. A planning-support tool for spatial suitability assessment of green urban stormwater infrastructure. Sci. Total Environ. 2019, 686, 856-868. [CrossRef] [PubMed]

11. Alves, A.; Vojinovic, Z.; Kapelan, Z.; Sanchez, A.; Gersonius, B. Exploring trade-offs among the multiple benefits of green-blue-grey infrastructure for urban flood mitigation. Sci. Total Environ. 2020, 703, 134980. [CrossRef] [PubMed]

12. Cohen, J.P.; Field, R.; Tafuri, A.N.; Ports, M.A. Cost Comparison of Conventional Gray Combined Sewer Overflow Control Infrastructure versus a Green/Gray Combination. J. Irrig. Drain. Eng. 2012, 138, 534-540. [CrossRef] 
13. Vojinovic, Z.; Keerakamolchai, W.; Weesakul, S.; Pudar, R.; Medina, N.; Alves, A. Combining Ecosystem Services with Cost-Benefit Analysis for Selection of Green and Grey Infrastructure for Flood Protection in a Cultural Setting. Environments 2016, 4, 3. [CrossRef]

14. Dong, X.; Guo, H.; Zeng, S. Enhancing future resilience in urban drainage system: Green versus grey infrastructure. Water Res. 2017, 124, 280-289. [CrossRef] [PubMed]

15. Alves, A.; Gersonius, B.; Kapelan, Z.; Vojinovic, Z.; Sanchez, A. Assessing the Co-Benefits of green-blue-grey infrastructure for sustainable urban flood risk management. J. Environ. Manag. 2019, 239, 244-254. [CrossRef]

16. Lehman, W.; Hasanzadeh Nafari, R. An Empirical, Functional approach to Depth Damages. E3s Web Conf. 2016, 7, 05002. [CrossRef]

17. Olesen, L.; Löwe, R.; Arnbjerg-Nielsen, K. Flood Damage Assessment-Literature Review and Recommended Procedure; Cooperative Research Centre for Water Sensitive Cities: Clayton, Australia, 2017.

18. Merz, B.; Kreibich, H.; Schwarze, R.; Thieken, A. Assessment of economic flood damage. Nat. Hazards Earth Syst. Sci. 2010, 10, 1697-1724. [CrossRef]

19. Corine Land Cover (CLC). 2012. Available online: https://land.copernicus.eu/pan-european/corine-landcover/clc-2012 (accessed on 28 July 2020).

20. Plavšić, J.; Vladiković, D.; Despotović, J. Floods in the Sava River Basin in May 2014. In Proceedings of the Mediterranean Meeting on Monitoring, Modelling, Early Warning of Extreme Events Triggered by Heavy Rainfall, Cosenza, Italy, 26-28 June 2014; Ferrari, E., Versace, P., Eds.; Luigi Pellegrini Editore: Cosenza, Italy, 2014; pp. 241-251.

21. UNDP Serbia. Studija unapređenja zaštite od voda u slivu reke Kolubare (Study of the Upgrade of the Flood Protection System in the Kolubara Watershed); Institute "Jaroslav Černi" for the United Nations Development Programme in Serbia and Public Water Management Company "Srbijavode": Belgrade, Serbia, 2016; Available online: https://studijakolubara.srbijavode.rs/izvestaji_o_rezultatima_studije/Друга-фаза/preliminarni_izvestaj/ (accessed on 10 September 2020).

22. Filazzola, A.; Shrestha, N.; MacIvor, J.S. The contribution of constructed green infrastructure to urban biodiversity: A synthesis and meta-analysis. J. Appl. Ecol. 2019, 56, 2131-2143. [CrossRef]

23. NWRM Natural Water Retention Measures, Catalogue of NWRM. Available online: http://nwrm.eu/measurescatalogue (accessed on 28 July 2020).

24. Kron, W. Flood Risk = Hazard • Values • Vulnerability. Water Int. 2005, 30, 58-68. [CrossRef]

25. Messner, F.; Penning-Rowsell, E.; Green, C.; Meyer, V.; Tunstall, S.; van der Veen, A. Evaluating Flood Damages: Guidance and Recommendations on Principles and Methods. FLOODsite Project Deliverable D9.1. 2007. Available online: http://www.floodsite.net/html/partner_area/project_docs/T09_06_01_Flood_ damage_guidelines_d9_1_v2_2_p44.pdf (accessed on 28 July 2020).

26. UN/ISDR. Living with Risk: A Global Review of Disaster Reduction Initiatives; United Nations Inter-Agency Secretariat of the International Strategy for Disaster Reduction (UN/ISDR): Geneva, Switzerland, 2004.

27. Wagenaar, D.; Lüdtke, S.; Schröter, K.; Bouwer, L.M.; Kreibich, H. Regional and Temporal Transferability of Multivariable Flood Damage Models. Water Resour. Res. 2018, 54, 3688-3703. [CrossRef]

28. Pistrika, A.; Tsakiris, G.; Nalbantis, I. Flood Depth-Damage Functions for Built Environment. Environ. Process. 2014, 1, 553-572. [CrossRef]

29. Stanić, M.; Todorović, A.; Vasilić, Ž.; Plavšić, J. Extreme flood reconstruction by using the 3DNet platform for hydrological modelling. J. Hydroinf. 2018, 20, 766-783. [CrossRef]

30. Brunner, G.W. HEC-RAS River Analysis System: Hydraulic Reference Manual; Hydrologic Engineering Center: Davis, CA, USA, 2016.

31. US Army Corps of Engineers. HEC-GeoRAS-GIS Tools for Support of HEC-RAS using ArcGIS, User's Manual; US Army Corps of Engineers: Davis, CA, USA, 2011.

32. Todorović, A.; Stanić, M.; Vasilić, Ž.; Plavšić, J. The 3DNet-Catch hydrologic model: Development and evaluation. J. Hydrol. 2019, 568, 26-45. [CrossRef]

33. Huizinga, J.; de Moel, H. SzewczykW Global Flood Depth-Damage Functions. Methodology and the Database with Guidelines; Joint Research Centre (European Commission): Ispra, Italy, 2017. [CrossRef]

34. Antolini, F.; Tate, E.; Dalzell, B.; Young, N.; Johnson, K.; Hawthorne, P.L. Flood Risk Reduction from Agricultural Best Management Practices. J. Am. Water Resour. Assoc. 2020, 56, 161-179. [CrossRef] 
35. FEMA. Supplement to the Benefit-Cost Analysis Reference Guide; Federal Emergency Management Agency: Washington, DC, USA, 2011.

36. The United Nations Refugee Agency (UNHCR); Bulevar Zorana Đinđića 64, Belgrade, Serbia. Personal communication, February 2020.

37. Olsen, A.; Zhou, Q.; Linde, J.; Arnbjerg-Nielsen, K. Comparing Methods of Calculating Expected Annual Damage in Urban Pluvial Flood Risk Assessments. Water 2015, 7, 255-270. [CrossRef]

38. Jongman, B.; Kreibich, H.; Apel, H.; Barredo, J.I.; Bates, P.D.; Feyen, L.; Gericke, A.; Neal, J.; Aerts, J.C.J.H.; Ward, P.J. Comparative flood damage model assessment: Towards a European approach. Nat. Hazards Earth Syst. Sci. 2012, 12, 3733-3752. [CrossRef]

39. Marvi, M.T. A review of flood damage analysis for a building structure and contents. Nat. Hazards 2020, 102, 967-995. [CrossRef]

40. FAO The impact of Natural Hazards and Disasters on Agriculture, Food Security and Nutrition; Food and Agriculture Organization of the United Nations: Rome, Italy, 2015; ISBN 978-92-5-108962-0.

41. Brémond, P.; Grelot, F.; Agenais, A.-L. Review Article: Economic evaluation of flood damage to agriculture review and analysis of existing methods. Nat. Hazards Earth Syst. Sci. 2013, 13, 2493-2512. [CrossRef]

42. Gerl, T.; Kreibich, H.; Franco, G.; Marechal, D.; Schröter, K. A Review of Flood Loss Models as Basis for Harmonization and Benchmarking. PLoS ONE 2016, 11, e0159791. [CrossRef] [PubMed]

43. Saint-Geours, N.; Grelot, F.; Bailly, J.-S.; Lavergne, C. Ranking sources of uncertainty in flood damage modelling: A case study on the cost-benefit analysis of a flood mitigation project in the Orb Delta, France. J. Flood Risk Manag. 2015, 8, 161-176. [CrossRef]

44. Highfield, W.E.; Norman, S.A.; Brody, S.D. Examining the 100-Year Floodplain as a Metric of Risk, Loss, and Household Adjustment. Risk Anal. 2013, 33, 186-191. [CrossRef]

45. Meyer, V.; Becker, N.; Markantonis, V.; Schwarze, R.; van den Bergh, J.C.J.M.; Bouwer, L.M.; Bubeck, P.; Ciavola, P.; Genovese, E.; Green, C.; et al. Assessing the costs of natural hazards—state of the art and knowledge gaps. Nat. Hazards Earth Syst. Sci. 2013, 13, 1351-1373. [CrossRef]

46. Apel, H.; Aronica, G.T.; Kreibich, H.; Thieken, A.H. Flood risk analyses-How detailed do we need to be? Nat. Hazards 2009, 49, 79-98. [CrossRef]

47. de Moel, H.; Jongman, B.; Kreibich, H.; Merz, B.; Penning-Rowsell, E.; Ward, P.J. Flood risk assessments at different spatial scales. Mitig. Adapt. Strateg. Glob. Chang. 2015, 20, 865-890. [CrossRef] [PubMed]

48. Kušar, S. Green Infrastructure as A Facilitator of Sustainable Spatial Development in Rural Areas: Experiences from The Vipava Valley (Slovenia). Eur. Countrys. 2019, 11, 17-28. [CrossRef] 